\title{
Off the scale: a new species of fish-scale gecko (Squamata: Gekkonidae: Geckolepis) with exceptionally large scales
}

\author{
Mark D Scherz ${ }^{\text {Corresp., }}{ }^{1}$, Juan Diego Daza ${ }^{2}$, Jörn Köhler ${ }^{3}$, Miguel Vences ${ }^{4}$, Frank Glaw ${ }^{1}$ \\ ${ }^{1}$ Sektion Herpetologie, Zoologische Staatssammlung München, Munich, Germany \\ 2 Department of Biological Sciences, Sam Houston State University, Huntsville, Texas, United States \\ 3 Hessisches Landesmuseum Darmstadt, Darmstadt, Germany \\ 4 Zoologisches Institut, Technische Universität Braunschweig, Braunschweig, Germany \\ Corresponding Author: Mark D Scherz \\ Email address: mark.scherz@gmail.com
}

The gecko genus Geckolepis, endemic to Madagascar and the Comoro archipelago, is taxonomically challenging. One reason is their ability to autotomize a large portion of their scales when grasped or touched, most likely to escape predation. Based on an integrative taxonomic approach including external morphology, morphometrics, genetics, pholidosis, and osteology, we here describe the first new species from this genus in 75 years:

Geckolepis megalepis sp. nov. from the limestone karst of Ankarana in northwestern Madagascar. The new species has the largest known body scales of any gecko (both relatively and absolutely), which come off with exceptional ease. We provide a detailed description of the skeleton of the genus Geckolepis based on micro-Computed Tomography (micro-CT) analysis of the new species, the holotype of G. maculata, the recently resurrected $G$. humbloti, and a specimen belonging to an operational taxonomic unit (OTU) recently suggested to represent G. maculata. Geckolepis is characterized by highly mineralized, imbricated scales, paired frontals, and unfused subolfactory processes of the frontals, among other features. We identify diagnostic characters in the osteology of these geckos that help define our new species and show that the OTU assigned to $G$. maculata is probably not conspecific with it, leaving the taxonomic identity of this species unclear. We discuss possible reasons for the extremely enlarged scales of $G$. megalepis in the context of an anti-predator defence mechanism, and the future of Geckolepis taxonomy. 
4 Off the scale: a new species of fish-scale gecko (Squamata: Gekkonidae: Geckolepis) with 5 exceptionally large scales

7

8 Mark D. Scherz ${ }^{1}$, Juan Diego Daza ${ }^{2}$, Jörn Köhler ${ }^{3}$, Miguel Vences ${ }^{4}$ \& Frank Glaw ${ }^{1}$

9

10 'Sektion Herpetologie, Zoologische Staatssammlung München, Munich, Germany.

$11{ }^{2}$ Department of Biological Sciences, Sam Houston State University, Huntsville, Texas, United

12 States

13 Hessisches Landesmuseum Darmstadt, Darmstadt, Germany

14 4Zoologisches Institut, Technische Universität Braunschweig, Braunschweig, Germany

15

16 Corresponding author: Mark D. Scherz, mark.scherz@gmail.com 


\section{ABSTRACT}

The gecko genus Geckolepis, endemic to Madagascar and the Comoro archipelago, is taxonomically challenging. One reason is their ability to autotomize a large portion of their scales when grasped or touched, most likely to escape predation. Based on an integrative taxonomic approach including external morphology, morphometrics, genetics, pholidosis, and osteology, we here describe the first new species from this genus in 75 years: Geckolepis megalepis sp. nov. from the limestone karst of Ankarana in northwestern Madagascar. The new species has the largest known body scales of any gecko (both relatively and absolutely), which come off with exceptional ease. We provide a detailed description of the skeleton of the genus Geckolepis based on micro-Computed Tomography (micro-CT) analysis of the new species, the holotype of $G$. maculata, the recently resurrected $G$. humbloti, and a specimen belonging to an operational taxonomic unit (OTU) recently suggested to represent G. maculata. Geckolepis is characterized by highly mineralized, imbricated scales, paired frontals, and unfused subolfactory processes of the frontals, among other features. We identify diagnostic characters in the osteology of these geckos that help define our new species and show that the OTU assigned to $G$. maculata is probably not conspecific with it, leaving the taxonomic identity of this species unclear. We discuss possible reasons for the extremely enlarged scales of G. megalepis in the context of an anti-predator defence mechanism, and the future of Geckolepis taxonomy.

\section{INTRODUCTION}

The genus Geckolepis Grandidier, 1867, endemic to Madagascar and the Comoros, comprises a complex of species that have proven particularly difficult to delimit (Köhler et al. 2009). Known as fish-scale geckos, they have unusually large, imbricate scales and are renowned for their ability to shed a large portion of their integument with extreme ease as a defence mechanism (Gardner \& Jasper 2015; Glaw \& Vences 2007; Schmidt 1911; Schubert \& Christophers 1985; Schubert et al. 1990; Voeltzkow 1893). Indeed, the process of collection often damages even the most intact specimens; Voeltzkow (1893) captured his specimens with bundles of cotton ('Wattebäuschen'), and even this was not sufficient to prevent some scale loss. This, and the irregularity of Geckolepis scalation (Schmidt 1911), makes meristics difficult to apply to them. These factors, combined with the secretive nature and cryptic colouration of this 
48

genus, have largely hindered progress on resolving its species taxonomy (Köhler et al. 2009; Lemme et al. 2013).

$$
\text { In their revision of this genus, Köhler et al. (2009) recognised three valid nominal species- }
$$
Geckolepis maculata Peters, 1880, G. polylepis Boettger, 1893, and G. typica Grandidier, 1867 - on the basis of pholidosis and morphometry, with G. petiti Angel, 1942, G. typica anomala Mocquard, 1909, and G. typica modesta Methuen \& Hewitt, 1913 considered junior synonyms of G. typica, and G. humbloti Vaillant, 1887 a junior synonym of G. maculata. Four years later, Lemme et al. (2013) published a molecular phylogeny of this genus spanning many localities in Madagascar, and compared their trees with a morphological dataset. They designated 11 provisional Operational Taxonomic Units (OTUs), divided into three large clades, with a further clade represented by just one gene constituting G. polylepis, falling sister to G. typica. Their results are summarised in Fig. 1. While two clades were easily assigned to nominal species (G. typica and G. polylepis), G. maculata was difficult to place due to uncertainty surrounding its type locality (see the supplementary information), but they tentatively assigned it to OTU AB. The other OTUs are apparently distinct from any described species. Lemme et al. (2013) therefore estimated that Geckolepis might, once fully resolved, contain around ten species.

Based on the DNA sequence data of Lemme et al. (2013), OTU D is the sister group of a clade containing OTU AB from northern Madagascar, and OTU C which is widespread along Madagascar's east coast (Fig. 1). OTU AB occurs at sites north (e.g. Montagne d'Ambre) and south (e.g. Manongarivo, Nosy Be) of the Ankarana Massif, the only site where OTU D has so far been found. The genetic differentiation of OTU D is strong, amounting to $6.2 \%$ uncorrected pairwise sequence divergence in the mitochondrial $12 \mathrm{~S}$ rRNA gene compared to OTU AB, and $7 \%$ to OTU C. Furthermore, OTU D did not share haplotypes with OTUs AB and C in the nuclear gene CMOS (Lemme et al. 2013).

Recently, Geckolepis humbloti was resurrected from synonymy with G. maculata, based on morphology, pholidosis, osteology, molecular phylogenetics, and biogeography (Hawlitschek et al. 2016). All specimens from the type locality of G. humbloti, Grand Comoro, and the other Comoro islands, are distantly related to all lineages from Madagascar except one in western Madagascar, which may belong to the ancestral population that colonised the Comoros. Thus, four species of Geckolepis are currently recognized, and since no specimens of G. humbloti were included in the molecular phylogeny of Lemme et al. (2013), the number of undescribed OTUs 
79 in this genus remains undiminished. The phylogenetic position of G. humbloti relative to the

80 clades and OTUs of Lemme et al. (2013) is not completely clear, but it is inferred to be sister to 81 the their Clade 3 (see Fig. 1).

82 Recent work has provided detailed descriptions of the external morphology of the holotypes

83 of the four currently recognised species of Geckolepis (Hawlitschek et al. 2016; Köhler et al.

84 2009), and has identified genetic lineages constituting probable new species (Lemme et al.

85 2013). Two important taxonomic tasks remain: to firmly assign a genetic lineage to G. maculata, 86 and to describe the outstanding cryptic lineages. The present study seeks to contribute to both of

87 these goals, and thereby to facilitate further work on this complex. We describe a

88 morphologically distinct form (OTU D from Lemme et al. 2013) as a new species, and provide a

89 detailed osteological description of the genus Geckolepis based on micro-Computed

90 Tomography (micro-CT) scans, with comparative reference to G. maculata, G. humbloti, the 91 new species, and a member of the OTU AB from Lemme et al. (2013) to lay a foundation for

92 osteological data as a part of the integrative systematics of this genus. We discuss the remarkably

93 large scale size of the new species in the context of an anti-predator defence mechanism and

94 earlier works on Geckolepis integument, and go on to highlight the next steps in the taxonomic 95 resolution of Geckolepis.

\section{MATERIALS AND METHODS}

Specimens were collected and euthanized before being fixed in $90 \%$ ethanol and transferred to $70 \%$ ethanol for long-term storage. The following institutional acronyms are used: Université d'Antananarivo Département de Biologie Animale (UADBA); Zoologische Staassammlung München (ZSM); Museum für Naturkunde, Berlin (ZMB). Field number FGZC refers to the zoological collections of Frank Glaw. This study involved no experiments on living animals.

Our description scheme follows the re-descriptions of Köhler et al. (2009) for direct comparability with currently recognised taxa. They make use of the following characters, which we directly replicate here (see Fig. 2): axilla to groin distance (Ax-Gr); number of canthal scales (CS) in a straight line along the canthal ridge between post-nasals and orbit; horizontal eye diameter (ED); eye-to-ear distance (EED), from posterior margin of the eye to anterior margin of the ear; head height $(\mathrm{HH})$, measured at the posterior margin of the eye; head length (HL), 
109 measured from snout tip to a point level with the anterior margin of the ear opening; maximum

110 head width (HW); number and fraction of infralabial scales (IFL), counted to one decimal place,

111 anterior to the point level with the anterior margin of the eye; interorbital distance (IOD),

112 measured on the dorsal surface of the head and corresponding to the narrowest point of the

113 underlying frontal bone; number of interorbital scales at level of mid-eye (IOS); number of

114 subdigital lamellae on free portion of the first toe (L1TF); total number of subdigital lamellae on

115 the first toe, including the divided one adjacent to the claw (L1TT); number of conspicuously

116 widened subdigital lamellae on the fourth toe (L4TE); total number of subdigital lamellae on the

117 fourth toe including divided one adjacent to claw (L4TT); number of scales around midbody

118 (MBS); horizontal length of a typical scale anterior to the eye in the loreal region (SAE); external

119 shank length (ShL); snout length (SnL), from the tip of the snout to the anterior margin of the

120 orbit; horizontal length of an average sized scale posterior to the eye in the temporal region

121 (SPE); number of supralabials to the level of mid-eye (SPL); snout-vent length (SVL); tail

122 length (TL); number of ventrals in one head length as defined above (VHL), counted at

123 midventer; number of ventral scales from postmentals to vent (VS), excluding the small scales

124 behind postmentals and those anterior to the vent. The 'size of a typical dorsal scale at midbody

125 (DBS)' was not measured because 'size' is ambiguous; instead, we measured the width and

126 length of a mid-dorsal scale. Additionally, the 'number of mid-dorsal scales (DHL), from snout

127 tip to a point level with the anterior margin of the ear opening' was not counted because this

128 definition is inconsistent with the values given by Köhler et al. (2009). Postmental state is given

129 following Lemme et al. (2013), but postnasal scale states are given following Köhler et al.

130 (2009), because they were not included in Lemme et al. (2013); see Fig. 2.

131 Measurements and meristics were performed by MDS using a digital calliper $(0.01 \mathrm{~mm}$

132 precision) to the nearest $0.1 \mathrm{~mm}$. Scale counts and finer measurements were performed using an

133 Olympus® (Tokyo, Japan) SZX-ILLK200 stereomicroscope.

134 The electronic version of this article in Portable Document Format (PDF) will represent a 135 published work according to the International Commission on Zoological Nomenclature (ICZN), 136 and hence the new names contained in the electronic version are effectively published under that

137 Code from the electronic edition alone. This published work and the nomenclatural acts it

138 contains have been registered in ZooBank, the online registration system for the ICZN. The

139 ZooBank LSIDs (Life Science Identifiers) can be resolved and the associated information viewed 
140 through any standard web browser by appending the LSID to the prefix http://zoobank.org/. The

141 LSID for this publication is: urn:lsid:zoobank.org:pub:12C9B971-CF0F-49B7-93B1-

142 0A480ACA9B53. The online version of this work is archived and available from the following

143 digital repositories: PeerJ, PubMed Central, and CLOCKSS.

144 The following specimens were micro-CT scanned for this study: Geckolepis maculata ZMB

145 9655; Geckolepis megalepis sp. nov. ZSM 2126/2007 (FGZC 1144) and ZSM 289/2004 (FGZC

146 554); Geckolepis sp. of OTU AB sensu Lemme et al. (2013) ZSM 1520/2008 (FGZC 1697).

147 Scans of Geckolepis humbloti produced for Hawlitschek et al. (2016) were re-analysed in this

148 study: ZSM 81/2006 (FGZC 836) and ZSM 80/2010 (FGZC 4029). Micro-CT scans were

149 produced using a phoenix $\mid \mathrm{x}$ nanotom ${ }^{\circledR}$ m cone-beam micro-CT scanner (GE Measurement \&

150 Control, Wunstorf, Germany) employing a tungsten or diamond target and a $0.1 \mathrm{~mm} \mathrm{Cu}$ filter.

151 Specimens were mounted and stabilised using polystyrene and small wooden braces, inside

152 polyethylene or polypropylene vessels containing a small amount of $75-80 \%$ EtOH to achieve

153 air saturation and prevent desiccation. Scans using the tungsten target were performed at $140 \mathrm{kV}$

154 and $80 \mu \mathrm{A}$; scans using the diamond target were performed at $100 \mathrm{kV}$ and $100 \mu \mathrm{A}$. Full body

155 scans were performed for 12 or 20 minutes (1440 or 2440 projections) with specimens mounted

156 at an oblique angle. Skull scans were performed for 20 or 30 minutes with 2440 projections at a

157 timing of 500 or $750 \mathrm{~ms}$ with specimens mounted vertically. For scanning details of G. humbloti,

158 see Hawlitschek et al. (2016). Volume renders were produced in VG Studio Max 2.2 (Visual

159 Graphics GmbH, Heidelberg, Germany) and Avizo Lite 9.0.0 (FEI Visual Sciences Group,

160 Burlington MA, USA). Osteological description follows terminology of recent anatomical

161 descriptions by Daza et al. (2008), Evans (2008), Russell \& Bauer (2008), and Daza \& Bauer

162 (2015) and is based on volume renders produced in VG Studio Max 2.2 and Avizo Lite 9.0.0.

163 Skeletal figures were prepared from volume renders produced in VG Studio Max 2.2 and Avizo

164 Lite 9.0.0. DICOM stacks of the scan files have been uploaded to MorphoSource.org and are

165 available at http://morphosource.org/Detail/ProjectDetail/Show/project_id/302

166 All field research and collecting of specimens were approved by the Malagasy Ministère de

167 l'Environnement, des Eaux et des Forêts (Direction des Eaux et Forêts, DEF) under the following

168 permits: 238-MINENVEF/SG/DGEF/DPB/SCBLF dated 14 November 2003; 298/06-

169 MINENV.EF/SG/DGEF/DPB/SCBLF/RECH dated 22 December 2006; 036/08

$170 \mathrm{MEEFT/SG/DGEF/DSAP/SSE} \mathrm{dated} 30$ January 2008; and 174/16/MEEF/SG/DGF/DSAP/SCB, 
171 dated 25 July 2016. Export of specimens was approved by the DEF under permits: 094C-

172 EA03/MG04, dated 1 March 2004; 051N-EA03/MG07, dated 10 March 2007, and 270N-

173 EA09/MG16, dated 7 September 2016.

174 RESULTS

175 Our analysis of three specimens of Geckolepis from the Ankarana Reserve assigned to OTU

176 D by Lemme et al. (2013) confirmed that these individuals are distinct in pholidosis from any

177 described species, having a lower number of larger scales than any other known populations of

178 Geckolepis. Micro-CT scans of the skeletons of these individuals and several congeners reveal

179 subtle differences in osteology between known species and lineages. For future reference we

180 listed 24 variable skull traits (Appendix 2) among Geckolepis that provide a baseline for future

181 comparative studies. Consequently, we here describe OTU D as a new species on the basis of

182 morphometrics, pholidosis, skeletal morphology, and molecular phylogenetics, and compare its

183 skeletal morphology in detail with those of individuals of G. maculata, G. humbloti, and OTU

184 AB sensu Lemme et al. (2013).

185

186 Geckolepis megalepis sp. nov.

187 Geckolepis sp. OTU D - (Lemme et al. 2013)

188 (Figs 3-6, 8-10, Table 1, Appendix 1)

189 LSID: urn:lsid:zoobank.org:act:08097CA5-172E-4F45-AE68-AC4E02BBC644

190

191

Holotype. ZSM 2126/2007 (FGZC 1144), an adult of unknown sex, from the east side of

192 Ankarana National Park (12.9564 S, 49.1172 ${ }^{\circ}$ E, ca. $150 \mathrm{~m}$ a.s.l.), Antsiranana Province, north

193 Madagascar, collected on 3 March 2007 by P. Bora, H. Enting, F. Glaw, A. Knoll \& J. Köhler.

Paratypes. ZSM 289/2004 (FGZC 554), probably a subadult, sex unknown, from between Mahamasina and the Petit Tsingy (exact coordinates not known, but ca. $12.9558^{\circ} \mathrm{S}, 49.1181^{\circ} \mathrm{E}$, ca. 125 m a.s.1.), Ankarana National Park, Antsiranana Province, north Madagascar, collected 25 February 2004 by F. Glaw, M. Puente \& R. Randrianiaina; ZSM 232/2016 (FGZC 5476), an adult of unknown sex, from the private forest of the Ankarana Lodge $\left(12.9613^{\circ} \mathrm{S}, 49.1499^{\circ} \mathrm{E}\right.$, 
200134 m a.s.1.), Ankarana massif, Antsiranana Province, north Madagascar, collected 28 August

2012016 by F. Glaw, K. Glaw, T. Glaw, Jaques, and N. A. Raharinoro; FGZC 1606 (UADBA

202 uncatalogued), sex and age unknown, from Petit Tsingy (ca. $12.9558^{\circ} \mathrm{S}, 49.1181^{\circ} \mathrm{E}$, ca. $125 \mathrm{~m}$

203 a.s.1.), Ankarana National Park, Antsiranana Province, north Madagascar, collected 12 February

2042008 by N. D'Cruze, M. Franzen, F. Glaw \& J. Köhler.

205 Diagnosis. A species of the genus Geckolepis based on its overall morphology and large, fish-

206 like scales (similar to cycloid scales in terms of the extent of overlap), as well as its phylogenetic

207 position (Lemme et al. 2013). Geckolepis megalepis differs from all of its congeners by the

208 possession of the following suite of characters: innermost pair of postmental scales in broad

209 contact (condition A/B, Fig. 4), SVL $\leq 69.5 \mathrm{~mm}$, infralabials to anterior margin of eye 4.5-4.8,

210 17-18 scales rows around the midbody, 27-31 ventral scales between the postmentals and the

211 vent, and the absence of a dark lateral stripe, and typical midbody dorsal scales measuring 7.3-

$2128.3 \%$ of the SVL. Osteologically, G. megalepis is characterised by a narrow infraorbital fenestra,

213 a bulging nasal cavity, nasals with straight sides, a well developed anterior extension of the

214 subfrontal process, a notched premaxilla-vomer fenestra, scapular ray of scapulocoracoid not

215 surpassing the clavicle, and posteriorly curved pubic tubercle of the pubis. Additionally, it is

216 separated by an uncorrected pairwise genetic distance in the mitochondrial ND4 gene of $\geq 10.1 \%$

217 from all other lineages of Geckolepis and has a unique CMOS haplotype (Lemme et al. 2013).

218 Geckolepis megalepis may be distinguished from G. maculata (note: because of the

219 substantial uncertainty surrounding the identity of G. maculata, we here compare G. megalepis

220 only to the holotype of that species, ZMB 9655, until such a time as its true affinities can be

221 clarified; see Köhler et al. (2009) for a detailed morphological account of that specimen) by the

222 combination of fewer scale rows around midbody (17-18 vs. 25$)$, fewer ventral scales (27-31 vs.

223 32), larger relative scale size (typical midbody dorsal scale 7.3-8.3\% of SVL vs. 5.4\%), and the

224 absence of a dark lateral head stripe (vs. presence); from G. typica by larger maximum size (SVL

225 up to $69.5 \mathrm{~mm}$ vs. $<57 \mathrm{~mm}$ ), fewer scale rows around midbody (17-18 vs. 28-32), fewer ventral

226 scales (27-31 vs. 42-49), postmental scale condition (A/B vs. D), and the absence of dark

227 longitudinal stripes on the dorsum (vs. presence); from G. polylepis by larger maximum size

228 (SVL up to $69.5 \mathrm{~mm}$ vs. $<52 \mathrm{~mm}$ ), fewer scale rows at midbody (17-18 vs. 30-37), fewer

229 ventral scales (27-31_vs. 37-55), and the absence of dark longitudinal stripes on the dorsum (vs.

230 presence); and from $G$. humbloti by fewer scale rows around midbody (17-18 vs. 22-30), more 
231 infralabials to the anterior margin of the eye (4.5-4.8 vs. 3-4), and fewer ventral scales (27-31 232 vs. 33-41).

233 For comparison of the osteology of the new species with Geckolepis maculata, G. humbloti, 234 and a specimen of OTU AB, see the Osteology of Geckolepis section below.

235

236

237

238

239

240

241

242

243

244

245

246

247

248

249

250

251

252

253

254

255

256

257

258

259

260

261

Description of the holotype. (Fig. 4) A large specimen in a moderately good state of preservation. Several scales missing from dorsum and the left knee, and a few older scars on the venter; tail detached but preserved, presumably autotomized during or after capture.

SVL $68.4 \mathrm{~mm}$; tail length $80.1 \mathrm{~mm}$; axilla-groin distance $27.2 \mathrm{~mm}$; shank length $5.8 \mathrm{~mm}$; head length $15.9 \mathrm{~mm}$; head width $16.1 \mathrm{~mm}$; head height $8.9 \mathrm{~mm}$; snout length $7.7 \mathrm{~mm}$; eye diameter $4.3 \mathrm{~mm}$; interorbital distance $8.7 \mathrm{~mm}$; eye-ear distance $5.0 \mathrm{~mm}$; rostral large, convex, distinctly visible from above; large postrostrals (4 supranasals) separated by a thin oblong scale anteriorly and two small scales posteriorly (type D); nostril bordered by rostral, first supralabial, three postnasals, and one supranasal (=postrostral); postnasals approximately equal in size to anterior loreals; postnasals and loreals separated by one row of small scales; scales on snout and on loreal region almost all with triangular posterior margins, slightly convex, imbricate; seven canthal scales in a line on the canthal ridge, including the postnasals, between nostril and anterior margin of eye; scales at supraorbital region similar to and continuous with those on top of head; scales increase by a factor of 1.68 from level of mideye to occipital region; ten scales along a straight line dorsally between orbits; three rows of small scales adjacent to anterior margin of eye, decreasing to two on the upper and two on the posterior margin of eye; pupil vertical; seven supralabials to below centre of eye (eight total) on left side, eight to below centre of eye (nine total) on right side, all of roughly equal size, the posterior-most two smaller than the rest; scales in temporal region larger by factor 2.25 than those in loreal region; ear opening much smaller than eye, horizontally oval; 4.5 infralabials to below level of anterior margin of eye, decreasing in size posteriorly; mental scale large, triangular, with convex anterior border; postmentals asymmetric: one large pair immediately posterior to mental scale with broad medial contact, followed on the right side by two postmentals of decreasing size, and on the left by one broader postmental with an irregular posteromedial border (condition A/B; Fig. 4); one row of small scales separating postmentals from anterior chin scales; chin and ventral body scales rhomboid with rounded triangular posterior margins, imbricate, gradually increasing to double size 
262 posteriorly, arranged in roughly regular rows; 29 scales along the midventral line (count

263 somewhat inhibited by ventral scarring) between postmentals and vent, not including smaller

264 scales adjacent to postmentals and anterior to vent; dorsal scales cycloid, larger than lateral or

265 ventral scales; 18 scales around midbody; anterior half of tail flat and rather wide (55\% of body

266 width), decreasing in width gradually, down to a thin tip; tail covered with scales similar to body

267 scales, but gradually decreasing in size posteriorly, a series of transversely expanded median

268 subcaudals present, starting roughly $20 \mathrm{~mm}$ from the base of the tail; 14 lamellae under first toe,

269 extending from the sole of the foot to the claw, and 21 under fourth toe, 12 of which are

270 noticeably expanded; claws exposed, non-retractile. A single midbody scale measures $5.0 \mathrm{~mm}$

271 wide by $5.8 \mathrm{~mm}$ long, and is therefore $7.8 \%$ of the SVL in length.

272 Colouration in preservative: Head dorsally homogenously greyish brown, laterally greyish-

273 brown flecked with darker and lighter areas posterior to eye and below mouth; no obvious dark

274 lateral stripe; dorsal scales greyish brown flecked with dark and pale spots; legs as dorsum;

275 ventrally dirty white; tail greyish brown with four dark transverse markings that do not continue

276 onto the whitish ventral surface; exposed dorsal skin brown, ventral skin whitish. No information

277 exists regarding the life colouration of the specimen.

278

279

Variation. (Figs 3-4) Both ZSM paratypes strongly resemble the holotype, but one (ZSM

280 289/2004) is much smaller and presumed subadult. Their measurements and meristics are provided as part of Table 1, and in full detail in Appendix 1. These specimens differ from the holotype in the following characters not provided in Appendix 1: scales increase by a factor of postnasal configuration of ZSM 232/2016 type A, 289/2004 type D; postmentals large, three or four pairs present: one large pair immediately posterior to mental scale with broad medial contact, followed two or three pairs of decreasing size (condition A); mid-dorsal scales range from $7.3 \%$ to $8.3 \%$ of SVL; tail of ZSM 289/2004 not especially broadened (regenerated) and greyish brown with three darker transverse markings that do not continue onto the whitish ventral surface; tail of ZSM 232/2016 broad at its base and narrows rapidly (at least partially regenerated); overall body colouration of ZSM 232/2016 is more grey than the other specimens,

291 though this may be because it is considerably fresher. In ZSM 289/2004, one scale on the dorsal

292 surface of the neck and one on left side of dorsal tail base are dark brown with a burned 
293 appearance. The animal in Fig. 3A has 4.8 infralabials to the anterior edge of the eye (see Fig.

294 2A), and we thus infer that this value can range from 4.5 to 4.8. From Fig $3 \mathrm{~A}-\mathrm{B}$, the colouration

295 in life is assessed to be mostly grey with dark spots on some scales, giving a mottled appearance.

296

297

Phylogenetic relationships. This species is closely related to a sister species pair formed by

298

OTUs $\mathrm{C}$ and $\mathrm{AB}$ (Lemme et al. 2013; Fig. 1), which are widely distributed in eastern and

299

northern Madagascar. Their taxonomic status will need to be assessed in more detail in future

300 work on this genus.

301

302

Habitat, natural history, and conservation status. Geckolepis megalepis was observed active

303 at night both in the rainy and dry seasons, on trees (see Fig. 3A-B) and tsingy limestone rock. When captured, these geckos showed a strong tendency to autotomize large parts of their scales, leading to partly 'naked' geckos without any visible (bloody) lesions (Fig. 3C). In a subjective comparison this tendency appeared to be even more developed than in other Geckolepis species.

The new species is only known from the dry deciduous forest among the limestone tsingy karst of Ankarana Reserve and its immediate vicinity, an area of $182 \mathrm{~km}^{2}$. Due to its likely limited distribution $\left(182 \mathrm{~km}^{2}\right)$, knowledge from only two threat-defined localities in the Ankarana massif, and the potential for rapid decrease in quality of the forests of that reserve and

311 the area around it due to illicit deforestation, anthropogenic fire, sapphire mining, and free-

312 ranging grazing of livestock (e.g. Hawkins et al. 1990) we propose that it be listed as Near

313 Threatened under the IUCN criteria.

314 Two other geckos endemic to Ankarana Reserve are assessed as Near Threatened

315 (Lygodactylus expectatus Pasteur \& Blanc, 1967) and Endangered (Phelsuma roesleri Glaw,

316 Gehring, Köhler, Franzen \& Vences, 2010). We defend the choice of Near Threatened instead of

317 Endangered for G. megalepis on the following grounds: although it satisfies IUCN criterion B1

318 sub-criterion a, it fails to qualify for Endangered under sub-criteria b or c, as we can only

319 identify potential threats; were these to be realised, then the species would immediately qualify

320 for Endangered, but until that point, it remains Near Threatened. The same cannot be said of $P$.

321 roesleri, as it lives on Pandanus plants, which are less common in Ankarana and potentially

322 harvested by humans, making the risk to it greater, while G. megalepis is more generalist in its 
323 habits. Our recent observation of several individuals in a short timespan suggests that the

324 population of Geckolepis megalepis in Ankarana is at least locally healthy.

325

326

327

Etymology. The specific epithet is derived from the two Greek stems $\mu \varepsilon \dot{\gamma} \alpha \varsigma$ (mégas) meaning 'very large' and $\lambda \varepsilon \pi i \varsigma_{\zeta}$ (lepís) meaning 'scale', and refers to the large size of the scales of this species in comparison to its congeners and other geckos, which aids also in its diagnosis.

Available names. Three junior synonyms currently exist within the genus Geckolepis that must be considered as possible earlier names for G. megalepis: G. typica anomala Mocquard, 1909, G. typica modesta Methuen \& Hewitt, 1913, and G. petiti Angel, 1942. Synonymy of G. anomala, G. modesta, and G. petiti with G. typica was discussed at length by Köhler et al. (2009). While this placement needs to be re-analysed in light of the genetic information produced by Lemme et al. (2013), Geckolepis megalepis can be distinguished easily from the type series of G. anomala, G. modesta, and G. petiti by its postmental scales (condition A/B vs. D in G. anomala, G. modesta, and G. petiti), and fewer scale rows at midbody (17-18 vs. 32 in G. anomala, 22-25 in G. modesta, and 28 in G. petiti).

Remarks. The living specimen depicted in Fig. 3 of Lemme et al. (2013) as OTU D is misattributed and does not belong to Geckolepis megalepis. Lemme et al. (2013) report 17-20 scale rows at midbody for this species; the reason for this discrepancy could not be established here, but we are confident in our counts. However, we also emphasise that their higher number would remain diagnostic in all of the comparisons presented above. Köhler et al. (2009) probably did not include any specimens of Geckolepis megalepis in their revision of the genus, as they did not consider any individuals with fewer than 22 scale rows at midbody.

\section{Osteology of Geckolepis}

Osteological comparisons. The scales of Geckolepis geckos are mineralized and resemble osteoderms (Fig. 5; see also Schmidt 1911). Among gekkotans, only Gekko gecko and Tarentola species (Bauer \& Russell 1989; Daza \& Bauer 2015; Schmidt 1911; Vickaryous et al. 2015) are 
353 Geckolepis differ from the osteoderms of G. gecko and T. mauritanica in that they are imbricate, 354 and not juxtaposed and adpressed against the skull bones. Geckolepis also differ from the 355 majority of extant gekkotans in having paired and unfused (both dorsally and ventrally) frontal 356 bones; we only found fused frontal bones in a large specimen of the OTU AB sensu Lemme et 357 al. (2013) from Montagne des Français ('AB specimen’ henceforth), which is the most osteologically distinct specimen from our sample.

Geckolepis megalepis and the AB specimen differ from other Geckolepis in having a narrow infraorbital fenestra. In these two taxa, the nasal cavity also bulges slightly more than in smaller Geckolepis specimens. There is some variation in the shape of the nasal bones, being rectangular (with straight sides) in G. megalepis and the AB specimen. Geckolepis humbloti has nasal bones with a sigmoid lateral edge instead of straight. The holotype of $G$. maculata has nasals with straight lateral edges (Fig. 7). Geckolepis megalepis and the AB specimen have a more anterior extension of the subfrontal process of the frontal in palatal view, fused in the AB specimen and not fused in G. megalepis; all others have a large notched area that does not extend anteriorly. Another distinct feature of G. megalepis was found in the shape of the premaxilla-vomer fenestra, being notched instead of rounded as in other Geckolepis.

There are also some differences in the postcranium, the lateral processes of the first five caudal vertebrae (pygial series) are curved laterally (vs. straight in G. maculata and G. humbloti); the scapular ray of the scapulocoracoid does not surpass the clavicle (vs. surpassing the clavicle in G. maculata); the secondary coracoid ray of the scapulocoracoid extends to the level of the posterior margin of the clavicular fenestra (vs. surpassing the posterior margin of the fenestra in G. maculata); and the pubic tubercle of the pubis is posteriorly curved (vs. more or less vertical in G. maculata and G. humbloti).

Skeletal description. In the following section, we present a generalised skeletal description of the genus Geckolepis. Data on G. humbloti is based on the scans produced for Hawlitschek et al. (2016), re-analysed for this study. The postcranial skeleton of the AB specimen was not assessed; our postcranial osteological description pertains only to G. humbloti, G. maculata, and G. megalepis.

As we have mentioned above, one key feature of Geckolepis is the presence of a dense covering of mineralized scales (Fig. 5). These mineralized scales, contrary to the osteoderms of 
384 adpressed against the skull. Schmidt (1911) referred to these scales as osteoderm, but noted that 385 they are unique in lacking bone cells (that is to say, they are not osteoderm in the strict sense).

386 He found that these mineralizations, which he showed to be formed from calcified tissue fibres,

387 roughly trace the outline of the scales, but are mostly confined to their middles and do not extend

388 into the keratinous scale. Our micro-CT data indicates that mineralization of scales is more

389 extensive, at least in the examined species; scales shown in Fig. 5 are very similar in dimensions

390 to what they look like in life (e.g. compare Fig. 5A with ZSM 2126/2007 in Fig. 4). The reasons

391 for this discrepancy are not clear, and will require further study. However, we can confirm that

392 these mineralizations do not extend to the tip of the scales, as can be seen by the soft-looking

393 distal edges of the scales in Fig. 5. Schmidt (1911) also found that mineralization was lacking

394 from specific scales, including the labials and postmentals and scales proximal to these, small

395 scales of the head including those around the eye and ears, and fingers and toes; they also

396 decrease in frequency in the tail scales beyond the first third. This pattern is recapitulated by our

397 micro-CT scans. In a new study by Paluh and colleagues (in review), these mineralized scales are

398 again suggested to be osteoderms, but we conservatively refer to them here as 'mineralized

399 scales' until their study is published.

400 The mineralized scales were digitally removed from all the CT scans to facilitate rendering of

401 the underlying bone surface and sculpturing. We also digitally removed the endolymphatic sacs.

402 Skull (Figs 5-7):

403 The skull of Geckolepis is the typical broad and depressed skull of geckos (Kluge 1967),

404 wedge shaped in lateral view. The left maxilla of the holotype of G. maculata (ZMB 9655) is

405 fractured, and the premaxillary and maxillary palatal shelves show some irregular holes. There is

406 no trace of fracture bones associated with these holes, so the cracks may have been caused by an

407 infection that healed during the animal's life, or may have resulted from fixation in formalin and

408 gradual decalcification over almost 150 years (although the skull and postcranial skeleton shows

409 no other signs of extensive decalcification). The remaining specimens examined are intact ( $G$.

410 megalepis, G. humbloti, and the AB specimen). Fig. 6 provides anatomical labels for most

411 features based on the holotype of G. megalepis, whereas Fig. 7 provides comparative images of

412 one adult specimen each of the three other species included for comparative purposes. Rotational

413 videos of these scans are provided as supplementary videos SV1-5. The skeleton of $G$.

414 megalepis paratype ZSM 289/2004 is not figured, as the resolution of our micro-CT scan of it is 
415 too low, and only some of its character states could be accurately determined (see Appendix 2); 416 these however largely agree with the holotype.

417 Cranium: Nares oriented anteriorly, bordered medially by premaxilla, ventrally by premaxilla 418 and maxilla, laterally by facial process of the maxilla, and dorsally by nasals. The orbits are 419 incomplete posteriorly, and they accommodate the majority of the circular eye (as defined by the 420 sclerotic ring). The orbits are oriented anterolaterally, possibly enabling some field of vision 421 overlap. They are formed by the maxilla and jugal ventrally, prefrontal anteriorly, frontal 422 dorsally, and postfrontal posterodorsally. A sclerotic ring is present, composed of 14 bones.

423 The premaxilla is fused, with isodont, sharply pointed teeth with 13 tooth loci, this being a 424 constant number among all Geckolepis specimens examined. The ascending nasal process is 425 short and forms a bony septum between the nares, tapering abruptly dorsally, where it briefly 426 overlaps the nasals. The palatal shelf contacts the vomer, defines an incisive foramen, and 427 contacts the maxillae laterally.

428 The maxilla possesses a large facial process and a relatively narrow palatal shelf, as well as a 429 long posterior process, an anterior process, and an anterior maxillary lappet on the lingual side of 430 the anterior process. The alveolar border bears deeply pleurodont, sharply pointed isodont teeth. 431 Tooth loci fluctuate between 35 and 40, 36 in G. megalepis and the AB specimen; G. maculata 432 presents the lowest tooth count, with 35 tooth loci. The maxilla is pierced by four to six 433 supralabial foramina. The posterior process is in contact with the jugal and ectopterygoid 434 posteromedially. The palatal shelf contacts the anterior lateral process of the palatine posteriorly. 435 The maxillary lappet contacts the vomer laterally and the premaxilla's posterior palatine shelf 436 ventrally, and does not extend to meet its contralateral. The anterior process contacts the 437 premaxilla. The facial process is broad and dorsolaterally convex, its dorsal margin sloped 438 downward from its posterior end to its anterior end, its posterior margin weakly (G. maculata, 439 one specimen of G. humbloti) or strongly curved (G. megalepis, the AB specimen, and one 440 specimen of $G$. humbloti) and in contact with the prefrontal; posterodorsally in contact with the 441 frontal, and dorsally in contact with the nasal.

442 The nasal is nearly rectangular (except by the curved anterior edge that forms the 443 posterodorsal margin of the nares), a small portion of the medial edge lies beneath the ascending 444 nasal process of the premaxilla, and the anterolateral margin borders a small gap with the facial 445 process of the maxilla; the lateral edge is straight in G. maculata, bulges slightly outward in $G$. 
446 megalepis and the $\mathrm{AB}$ specimen, and is curved with a lateral flange overlapping the maxillary 447 facial process in G. humbloti (as seen in other geckos; Evans 2008); laterally in broad contact 448 with maxillary facial process, and posteriorly in contact with the frontal. Nasals are partially 449 fused in the AB specimen.

450 The prefrontal is strongly convex and has an extensive overlap with the facial process of the 451 452 maxilla, leaving the exposed surface roughly crescent-shaped in all species (slightly more crescentic in G. megalepis and some individuals of $G$. humbloti). The posterior edge is weakly 453 454 bowed and curves posteromedially forming the orbito-nasal flange. Dorsally it is distantly separated from the postorbitofrontal. The prefrontal and the maxilla bound the lacrimal foramen.

The frontal remains paired, and unfused to its contralateral — this state may however change with age, as the $\mathrm{AB}$ specimen has at least partially fused frontals, although a partial suture is still visible anteriorly and posteriorly (see Fig. 7A). It is in anterior contact with the nasal (straight or slightly concave suture), lateral contact to the facial process of the maxilla (concave suture) and the prefrontal (convex suture), posterolateral contact with the postorbitofrontal (which clasps the frontoparietal suture), and an extensive frontoparietal suture that is weakly curved anteriorly. The anterior end is overlapped by the nasal bones, and the visible portion is roughly half the width of the posterior end, the narrowest point being at the interorbital point. The subolfactory processes of the frontals contact each other but they remain separated, so there is also no ventral fusion. This condition is extremely rare in gekkotans, known only in the fossil Gobekko cretacicus (Daza et al. 2013). The crista cranii of the frontals are sutured to the medial side of the posterodorsal process of the prefrontal, thereby forming the dorsal and anterior orbital ridge. The frontal lacks significantly extended anteromedial and anterolateral processes.

The jugal is elongated and slender with tapered ends. It extends from the posterior process of the maxilla anteriorly along its medial edge, in contact with the ectopterygoid ventromedially, almost extending far enough forward to meet the palatine and participate in the lacrimal foramen.

The parietal is in broad medial contact with its contralateral, the suture is straight in $G$. maculata and zigzags in G. megalepis, G. humbloti, and the AB specimen, although in the lattermost there is also partial fusion, rendering the suture faint. The parietal also contacts the postorbitofrontal anterolaterally, crista alaris of the prootic lateroventrally, and the squamosal posterolaterally. The bone is broad, curved downwards forming some lateral protection for the brain. It is subtrapezoidal in shape, its lateral and median margins subparallel, the anterior 
477 margin angled posteriorly along the frontoparietal suture, the posterior margin angled anteriorly.

478 The posteroparietal process is long and thin in G. maculata and one specimen of G. humbloti, 479 and broad and short in G. megalepis, one specimen of G. humbloti and the AB specimen, 480 extending posterolaterally from the posterolateral corner of the parietal to contact with the 481 squamosal.

482 The postorbitofrontal is laminar: thin, short, and curved, extending just anterior and posterior 483 to frontoparietal suture and bracing it (Daza et al. 2008; Rieppel 1984), in contact with frontal 484 anteromedially and parietal posteromedially. It lacks a discrete free process for the attachment of 485 the postorbital ligament (Evans 2008), which might instead be anchored to the body of the bone.

486 The squamosal is short, slender, and curved, contacting the posterolateral process of the 487 488 parietal anteromedially, and the paroccipital process posteriorly. It is considerably reduced in $G$. maculata.

The quadrate has a deep indentation in the conch. This bone meets the quadrate process of the 490 pterygoid ventrally and has suspension formed by ligaments of the squamosal and the paroccipital processes; it is not in direct contact with any other bones. It has a thick central column and a thin, posterolaterally directed conch that lacks an obvious squamosal notch dorsally. Its cephalic condyle is dorsomedial and not strongly expanded. Its mandibular condyle is concave. It possesses a large foramen in the ventral half of the conch.

The septomaxilla is very thin, U-shaped, in anterior contact with the premaxilla, otherwise suspended in the nasal capsule. Its medial arm contacts the contralateral, separated anteriorly by a small foramen lying dorsal to the incisive foramen of the vomer. The lateral arm ascends slightly, and is long and cuneate with a sculpted lateral surface.

The vomer is a thin, laminar bone. It is strongly fused to its contralateral, though a median ridge allowing the individual bones to be distinguished despite strong ontogenetic fusion. Anteromedially an incisive foramen is present between the vomer and the posterior palatal shelf of the premaxilla, the shape of this foramen is variable among the species examined, being a vshaped notch (G. megalepis and G. maculata) or oval shaped (G. humbloti and the AB specimen). The anterolateral extension of vomer is in contact with the lingual maxillary lappet.

505 Posteriorly it bears two slender lateral processes, and the paired elements form a broad median 506 projection. The lateral process curves medially to join the vomerine process of the palatine. The 
507 median spur is bordered on either side by the distal tips of the palatine vomerine processes, and

508 forms the anterior end of the interpterygoid vacuity. The vomer has also two foramina that might 509 correspond to openings of the lacrimal duct.

510 The palatine is squarish, with rounded lateral and medial edges. The vomerine flange and 511 maxillary process are slender and subequal in length, together forming the border of the choana.

512 The vomerine flange lies parallel to the posterior processes of vomer and rests on a notch on the

513 body of the vomer; the maxillary process contacts the maxilla's palatal shelf laterally. The

514 palatine forms the anteromedial border of the suborbital fenestra. The bone is without an obvious

515 pterygoid process but possesses a posteroventral shelf where the palatine process of the

516 pterygoid overlaps it. Lateral to this overlap, the bone borders a slit extending medially from the

517 suborbital fenestra between the palatine and pterygoid. The medial edge of the palatine forms the

518 lateral border of interpterygoid vacuity. The lateral face of the palatine is in contact with the

519 anterolingual end of the ectopterygoid. The pterygopalatine joint is oblique.

520 The pterygoid is roughly y-shaped, with a brief anteromedial articulation with the palatine and 521 anterodorsal articulation with the ectopterygoid, articulating with the epipterygoid at the fossa 522 columellae, and contacting the quadrate posterolaterally. The pterygoid has a palatine process 523 anteromedially and a sculpted anterior border that is straight lateral to the palatine process,

524 forming the posterior border of a slit extending medially from the suborbital fenestra - then 525 concave, forming the posterior border of the suborbital fenestra - then extending anteriorly again 526 to form the pterygoid flange in contact with ectopterygoid, practically excluding the 527 ectopterygoid from the posterior margin of the suborbital fenestra; also forming the 528 posterolateral border of interpterygoid vacuity. The facet that contacts the basipterygoid process 529 is porous. In lateral view, the quadrate process curves laterally beyond this point and the fossa 530 columellae to below the quadrate.

531 The ectopterygoid is bent downward. It is anterolaterally in contact with the jugal, and 532 posteriorly in ventrolateral contact with the anterolateral pterygoid flange. The bone's downward 533 bend is due to the more dorsal position of palatine and maxilla relative to the pterygoid. Its 534 medial margin is sigmoid in G. maculata and G. humbloti, variable in G. megalepis (wavy in 535 ZSM 2126/2007 but sigmoid in ZSM 289/2004), and wavy in the AB specimen. The suborbital 536 fenestra is roughly teardrop shaped, pointed anteriorly and rounded posteriorly, formed by the 537 ectopterygoid laterally, pterygoid posteriorly, palatine anteromedially, and maxilla 
538 anterolaterally. The suborbital fenestra is broad in G. megalepis and the AB specimen and 539 narrow in all the remaining specimens examined.

540 The epipterygoid is columnar, tilted posteriorly, and appears mildly medially bowed in $G$. 541 megalepis, vertical or even externally bowed in G. humbloti, and vertical in G. maculata. It 542 extends from the foss a columellae of the pterygoid toward, but not into contact with, the crista 543 alaris of the prootic. The dorsal end is somewhat broader than the rest of the bone. The 544 interpterygoid vacuity is hourglass shaped, but broadens more rapidly posteriorly than anteriorly, 545 and is anteriorly bifurcated as a result of the medial spur of the vomer. The stapes has an oval 546 footplate that fits in the fenestra ovalis, and two posts extending laterally from footplate, one 547 anterior, the other posterior, converge to form the stapedial stem, leaving an open stapedial 548 foramen. The fenestra ovalis is posterior to the quadrate.

549 The basioccipital underlies most of the braincase, is slightly wider than long, and lacks a 550 distinct basal tubera. It is in contact with the parabasisphenoid anteriorly, otooccipitals laterally, 551 and forms the ventral component of foramen magnum. It is excluded from participation in the 552 lateral aperture of the recessus scala tympani by the otooccipital. It is posterolaterally bordered 553 by anteroventral extensions of the otooccipitals forming the sphenooccipital tubercle, which is 554 connected to a sharp crista tuberalis.

555 The parabasisphenoid is in contact with the prootic dorsally and basioccipital posteriorly. It 556 possesses a short, pointed parasphenoid rostrum, which is an extension of the squared anterior ends of the cristae trabeculae. The basipterygoid processes diverge anterolaterally, broadening distally, with flat, curved distal ends forming a synovial joint with the corresponding fossa of the posterior pterygoid (Payne et al. 2011). The vidian bridge extends to the base of the basipterygoid process from the crista prootica of the prootic. Posteriorly, the crista sellaris forms the anterior wall of the sella turcica. It has two pairs of anterior openings: carotid canals opening anteromedially, and the anterior openings of the Vidian canal anterolaterally, parallel to the basipterygoid processes.

The supraoccipital contacts the prootic anteriorly and otooccipitals ventrally, forming the dorsal edge of the foramen magnum. The posterior semi-circular canal extends posteriorly to the dorsal margin of the foramen magnum. The supraoccipital has a pair of dorsal tubercles that project dorsally without contacting the parietal; these tubercles are on either side of the midline of the holotype of G. megalepis, but are not strongly raised in any other specimen examined. 
The prootic is thin and has a prominent, triangular crista alaris. It is in contract with the

570

571

572

573

574

575

576

577

578

579

580

581

582

583

584

585

586

587

588

589

590

591

592

593

594

595

596

597

598

599 descending parietal process dorsally, the parabasisphenoid anteroventrally, supraoccipital posterodorsally, otooccipital posteroventrally, and almost in contact with the epipterygoid at the end of the crista alaris. The posterolateral margin forms the anterior wall of the fenestra ovalis, and the posteromedial surface forms the anterolateral wall of the brain case. The anterior semicircular canal runs through the base of the alary process and crista alaris. The horizontal semicircular canal and the ampullar bulge are visible in the posterior edge of the prootic. A projection from the crista alaris extends anteromedially down to the crista sellaris of the sphenoid and contains the trigeminal foramen (Daza et al. 2013), flaring also anterolaterally to the level of the epipterygoid from the base of the crista alaris.

The otooccipital is in contact with the prootic anteriorly, basioccipital ventromedially, supraoccipital dorsally, and the squamosal on the anterior face of the distal end of the paroccipital process. The horizontal and posterior semi-circular canals are visible as a bulge in posterior view. The occipital recess is enclosed in its posteroventral face. Anterodistally it projects ventrally to participate in the sphenooccipital tubercle with the basioccipital. The paroccipital process is long and thin, but broad dorsoventrally.

The foramen magnum is suboval, formed by the supraoccipital dorsally, otooccipitals lateroventrally, and basioccipital ventrally. The occipital condyles are double, formed by the otooccipitals laterally and the basioccipitals medially.

Jaw (Fig. 6D-E):

The jaw curves medially anteriorly, and forms a weak symphysis with its counterpart. The dentary is the longest bone, being tubular and enclosing the Meckelian canal, which becomes broader posteriorly, as it approaches the mandibular fossa. It bears isodont, pleurodont, somewhat conical and some recurved teeth. Tooth loci varies considerably from 27 to 40, the smallest number on the left ramus of the specimen $A B$, but it seems like this specimens has a pathological condition since the number is higher on the other side, reaching the base of the coronoid eminence. The interdental space is larger in the specimen $\mathrm{AB}$, which also explains the lowest number. Maximum tooth loci is roughly 34 in G. maculata, 37 in G. megalepis, and 40 in G. humbloti; with some teeth clearly missing in all specimens). Five mental foramina are present in the holotype, six in the paratype ZSM 289/2004 of G. megalepis. Posteriorly, the dentary contacts the surangular portion of the compound bone by superior and ventral processes, the 
600 latter extending considerably further than the former. The Meckelian canal is not outwardly

601 pronounced, and opens anteriorly below the symphysis.

602 The splenial is a thin, triangular, and flat bone that forms the medial wall of the Meckelian 603 canal, posterior to the tubular portion. It has two discrete foramina, the anterior inferior dental 604 foramen and the anterior mylohyoid foramen.

605 The coronoid has a strong and fin-like dorsal eminence with a broadened anterior edge, but its 606 precise shape varies within species. It inserts into the dentary at the level of the last or 607 penultimate tooth (except on one side of the jaw of the AB specimen, as mentioned above). The 608 posteromedial process reaches the middle of the surangular, anterior to the distinct mandibular 609 fossa. The triangular splenial is present on the lingual surface of the mandible, in contact with the 610 posteromedial surface of the dentary, the lingual anteroventral face of the coronoid, and the 611 lingual surface of the surangular.

612 The dorsal edge of the surangular portion of the compound bone is concave. The Meckelian 613 canal is closed, extending into the dentary from the adductor fossa. Surangular and posterior 614 surangular foramina are located in the labial side of the compound bone. An external foramen for 615 the chorda tympani is present at the base of the retroarticular process of the compound bone. The 616 length, width, and concavity of the retroarticular process are variable within species probably 617 due to scaling of the jaw muscles. The retroarticular process is strongly laterally notched, with a 618 medial ridge on its articular surface.

619 Axial Skeleton (Fig. 8): 26 presacral, two sacral, and a varying number of caudal vertebrae 620 are present (the total number cannot be ascertained due to autotomized or regenerated tails in all 621 scanned specimens). Of the presacrals, eight are cervical (defined as being anterior to first 622 vertebra possessing a rib reaching the sternum), sixteen or seventeen are thoracic (rib-bearing), 623 and one or two lack ossified ribs and are thus considered lumbars.

624 The atlas has an unfused neural arch, which is also not fused to the centrum, each side with a 625 short dorsolateral posterior projection not overlying the axis. The odontoid process of the axis 626 extends forward between the walls of atlas and into the braincase, fitting in between the occipital 627 condyles. The anterior three cervical vertebrae (atlas, axis, and third cervical) lack ribs. The 628 following five bear ribs of increasing length, all of which are to some degree dorsoventrally 629 broadened. 
630 The vertebrae are notochordal amphicoelous type (Romer 1956). The ribs of the first four 631 thoracic vertebrae reach the sternum - the fourth via the xiphisternum - followed by seven 632 vertebrae articulating with long, posteriorly arching ribs distally associated with postxiphisternal 633 inscriptional ribs, followed by five or six vertebrae possessing shorter ribs gradually becoming 634 more posteriorly curved (see Fig. 8B); one or two lumbar vertebrae follow that are similar in 635 shape to the posterior thoracic vertebrae but lack ribs.

636 The sacral pleurapophysis of the first sacral vertebra juts slightly posteriorly, articulating 637 distally with the pelvic girdle. The posterodistal edge is fused to the anterior edge of the 638 pleurapophysis of the second sacral vertebra, forming the foramen sacrale. The second sacral 639 vertebra possesses a dorsoventrally thin posterior crista comprising almost half the distal breadth 640 of the pleurapophysis (with asymmetrically emarginated distal edges in G. megalepis specimens: 641 more emarginated on the left than the right in ZSM 2126/2007 and right than left in ZSM 642 289/2004);

643 The first five caudal vertebrae possess long thin lateral processes, initially extending beyond 644 the sacrals, gradually decreasing in breadth, jutting posterolaterally, straight in G. maculata and 645 G. humbloti, curved laterally in G. megalepis, becoming increasingly posterior-jutting. The first 646 three caudals lack hemal arches.

647 Pectoral Girdle (Fig. 9): The pectoral girdle is comprised of paired clavicles, epicoracoids, 648 and scapulocoracoids, and a non-paired interclavicle and presternum.

649 The presternum is kite-shaped, and varies in ossification levels from poorly to fully ossified. 650 It has a synchondrotic articulation with the first three sternal ribs along its posterolateral border, 651 but lacks distinct facets for these. Its anterolateral edges are thickened to form the coracosternal 652 groove. No frontanelles are present. The mesosternal extension of the xiphisternum is variably 653 long, but poorly ossified.

654 The sagittal interclavicle is posteriorly arrowhead-shaped, and extends less than one third into 655 the sternum. It is anteriorly elongated, tubular and tapering, extending between the clavicles but 656 not beyond them.

657 The suprascapular and epicoracoid regions are at least partly ossified, but never completely. 658 The scapulocoracoid is typical in being composed of a horizontal plate (coracoid portion) and a 659 vertical lateral ascending process (scapular portion). No clear suture of the scapula and coracoid 
660 is visible in the micro-CT scans. The coracoid portion is broad, plate-like, with a bulbous process 661 at its posterolateral corner. The scapular portion is long, at least as long as the coracoid portion.

662 Three rays are present, all of which are directed anteromedially: The scapular ray is slender, and 663 passes dorsally anterior to the ascending lateral process of the clavicle in G. maculata, but does 664 not surpass the clavicle in G. megalepis or G. humbloti-it defines the dorsal edge of the 665 scapulocoracoid fenestra, which is ventrally completed by the primary coracoid ray. The 666 secondary coracoid ray extends to the level of the clavicular fenestra in G. maculata, and to the 667 level of the posterior margin of the clavicular fenestra in G. megalepis and G. humbloti. The rays 668 define four fenestrae: the secondary coracoid fenestra (medial scapulocoracoid+secondary 669 coracoid ray); the primary coracoid fenestra (secondary coracoid ray+primary coracoid ray); the 670 scapulocoracoid fenestra (primary coracoid ray+scapular ray; and the scapular fenestra (scapular 671 ray+distal scapulocoracoid). Anteriorly, all four fenestrae are closed by the cartilaginous

672 epicoracoids, which are not rendered in our micro-CT scans (see Fig. 9). This formation is type 6 673 sensu Lécuru (1968). The supracoracoid foramen is small, lying closer to first coracoid fenestra 674 than to the glenoid fossa.

675 The clavicle curves posteriorly and dorsally from the midline. It articulates with the ossified 676 acromion process of the poorly ossified suprascapula. It is angled posterolaterally, with a broadly

677 expanded but dorsoventrally flat medial portion — containing a large, oblong clavicular

678 fenestra - and slender curving lateral portion. It articulates at the midline with its contralateral 679 and the interclavicle, and is dorsally exceeded or at least overlapped by the epicoracoid cartilage 680 and parts of the suprascapular rays.

681 Forelimbs (Fig. 9): The humerus is marginally longer than the radius and ulna. It is somewhat 682 sigmoidal in dorsal view, with expanded proximal and distal ends. The proximal end is slightly 683 less broad than the distal end. It possesses prominent humeral and deltopectoral crests (the latter 684 with a sharp break separating it from the rest of the proximal humerus dorsally), as well as a 685 moderately developed ectepicondylar crest and ectepicondyle. The bicipital fossa is deeply 686 concave. The ectepicondylar foramen is visible in posterior view. In summary, it is fairly typical 687 of gekkonids (Russell \& Bauer 2008).

688 The radius is long and thin, slightly dorsoventrally flattened and weakly curved, with its distal 689 articulatory facet with a distinct processus styloideus; its distal end articulates with the radiale 690 posteriorly. The ulna is slender, dorsoventrally flattened, and straight, narrowing distally, but 
691 flaring at its distal end, where it articulates with the ulnare laterally and pisciform ventrally. The

692 olecranon process is clearly distinct, and proximal to it, on the articular surface of the humerus,

693 lies the sesamoid patella ulnaris, which is rounded. The internal face of the olecranon process

694 forms a smooth signmoid notch.

695 The spatium interosseum is formed by the diverging radius and ulna proximally and the 696 ulnare, centrale, and radiale distally, rendering it roughly teardrop shaped.

697 Nine carpal elements are present: The ulnare and radiale are subequal in size. The centrale is 698 thin and long, and lies between these two elements. The pisciform is small and rounded, lies

699 below the ulnare, and is probably not a true carpal (Russell \& Bauer 2008). A further five distal 700 carpals are identifiable, the first in contact with phalange I, second with phalange II, third with 701 phalanges II and III, fourth with phalanges III and IV, and fifth with phalange V. The phalangeal 702 formula is 2-2-3-4-2.

703 The first phalange of the first finger, first of the second finger, first and second of the third 704 finger, first through third of the fourth finger, and first of the fifth finger, are dorsoventrally 705 flattened and laterally broadened. The terminal phalanges of each toe are slender and arcuate, 706 ending in a laterally compressed, square tip with a distal claw-like projection, underlying the 707 claws proper. The digits are able to hyperextend significantly. These three characters are 708 presumably related to the adhesive pads of the fingers (Russell \& Bauer 2008). No ossified 709 paraphalangeal elements are present in the micro-CT scans.

710 Pelvis (Fig. 10): The pelvis is composed of fused paired ilia, ischia, and pubes. The 711 ischiopubic fenestra formed by the ischia and pubes is cardioid in shape, anteriorly rounded at 712 the medial symphysis of the pubes in G. maculata, but more pointed in G. megalepis and G.

713 humbloti - this fenestra may be medially divided by a proischiadic cartilage, but only the 714 posterior-most portion of this element is shown in our micro-CT scans.

715 The pubis and ischia are broad and thin, concave in ventral view. The ilium is long, 716 dorsoventrally broadened but laterally thin, and curves posteriorly. In lateral view (Fig. 10B), the 717 iliac blade is reminiscent of the shoes of the Greek god Hermes - it rises posterodorsally, and is 718 in broad medial contact with the pleurapophysis of the first sacral, and brief medial contact with 719 the anterior portion of the pleurapophysis of the second sacral. Anterolaterally the ilium 720 participates in the dorsal portion of the acetabulum. 
721

722

723

724

725

726

727

728

729

730

731

732

733

734

735

736

737

738

739

740

741

742

743

744

745

746

747

748

749

The epipubic cartilage anterior to the medial pubic symphysis is somewhat calcified.

The pubis curves from the anterior acetabulum ventrally and medially to the anterior symphysis with its contralateral at the front of the pelvis. It has a strong, medioventrally jutting pubic tubercle on the posterior portion of its lateral edge (see p. 138-145 in Russell \& Bauer (2008) for discussion of terminology), which descends more or less vertically in G. maculata and G. humbloti, but is posteriorly curved in G. megalepis. Medial to this is the concavo-convex pubic apron, the anterolateral edge of which runs anteromedially toward the medial symphysis with the contralateral pubis. The relatively large obturator foramen lies posterior to the pelvic tubercle, in line with the medial edge of the acetabulum.

Dorsolaterally, the ischium forms the posterior margin of the acetabulum. Ventromedially, it is roughly equal in breadth to the pubis, broadening toward the posteromedial symphysis with its contralateral at the back of the girdle. It possesses an almost lateral-pointing ischiadic tuberosity, rendering the posterolateral margin of the ischium deeply concave. The anterior margin of the ischium is also concave, extending anteriorly to form a weak prong, associated with the proischiadic cartilage. The medial ischial symphysis is not strongly fused, and the cartilaginous hypoischium likely extends into it.

A pair of curved post-cloacal bones is present in one specimen (ZSM 2126/2007; Fig. 10), but is absent from all other specimens. These may be sexually dimorphic and/or age dependent; see Russell et al. (2016) for a review of their phylogenetic distribution and evolution.

Hindlimbs: The femur is slender and weakly sigmoidal, with broad terminal ends. The epiphyseal internal trochanter is strong, and lies distal to the femoral condyle, from which it is separated by a deep notch. Its shape differs slightly among species: in G: megalepis, it is distinct and bulbous, in G. maculata it is ridge-like without a bulbous end, and in G. humbloti it is variable, with one specimen (ZSM 81/2006) resembling G. megalepis and one (ZSM 80/2010) resembling G. maculata. The ventral face of the proximal end of the femur has a moderately deep intertrochanteric fossa. The lateral distal condyle is distinctly larger than the medial one. The distal intercondylar groove is pronounced, and the popliteal fossa is not strongly deepened. The fibula articulates via a sesamoid cyamella (=parafibula) with the lateral surface of the posterior femoral condyle. Additional sesamoids include the lenticular tibial patella dorsal to the 
750 distal end of the femur, a spherical post-axial ligament sesamoid (fabella), and the tibial lunula

751 between the tibia and femur.

752 The fibula is laterally flattened to a slender rod of bone, with a slightly broader distal than

753 proximal end. The tibia is broad and dorsoventrally compressed, and bows slightly outward. The

754 cnemial and ventral crests are not pronounced and may be absent. Together the tibia and fibula

755 articulate with the subtriangular astragalocalcaneum, which in turn articulates with the first

756 metatarsal and the fourth distal tarsal. Two distal tarsals are present (third and fourth; see Russell

757 \& Bauer (2008) for discussion of terminology). The fifth metatarsal is L-shaped and bears

758 distinctly raised anterior and posterior plantar tubercles. The second metatarsal is longer than the

759 fourth, and the third is the longest. The pedal phalangeal formula is 2-2-3-4-3.

760

761 DISCUSSION

762 Geckolepis megalepis is the first Geckolepis species to be described in 75 years (and it has

763 been 123 years since the last currently recognised species was described). Although far northern

764 Madagascar is relatively well surveyed for reptiles, and numerous Geckolepis populations have

765 been recorded from this area, the new species has not been found outside the Ankarana massif.

766 Considering the increasing number of squamate species putatively endemic to this spectacular

767 limestone formation (Glaw et al. 2010; Glaw et al. 2012; Jono et al. 2015; Ruane et al. 2016), it

768 is likely that G. megalepis will also turn out to be microendemic to the region; unusual among

769 Geckolepis species. In Ankarana, it occurs in sympatry with another lineage of Geckolepis (OTU

$770 \mathrm{G}$ in Lemme et al. 2013), which also may be microendemic to this area, but to which it is only

771 distantly related (uncorrected pairwise distance $11.3 \%$ in $12 \mathrm{~S}$ rRNA according to sequences

772 published by Lemme et al. 2013). The new species can be distinguished from these geckos by the

773 lack of a dark stripe from eye to ear opening (vs. presence), possession of 17-18 scale rows at

774 midbody (vs. 25-28), and possession of 27-31 ventral scale rows (vs. 33-43) (Lemme et al.

775 2013).

776 Extreme integumentary autotomy in Geckolepis megalepis

777 Many reptiles have evolved the ability to shed some part of their body in response to predator

778 attack. The most widespread form is caudal autotomy, the shedding of all or part of the tail,

779 which is widespread among lepidosauria, from amphisbaenians to rhynchocephalians, even being 
780 found in some snakes (Arnold 1984; Bateman \& Fleming 2009). Geckolepis species are also able

781 to shed their tails, and indeed few specimens survive to adulthood with their original tails intact

782 (see for instance Fig. 3A-B). In addition, these geckos have evolved an even more extreme

783 adaptation, i.e. the autotomy of virtually their entire integument when seized or even touched.

784 Earlier studies have shown that the autotomized layers include epidermis, underlying connective

785 tissue, and subcutaneous fat tissue, and that a layer between the integument and the underlying

786 tissue represents a pre-formed splitting zone (Schubert \& Christophers 1985). The shedding

787 process is most likely achieved by contraction of the network of myofibroblasts in the pre-

788 formed splitting zone, with vasoconstriction in the most superficial vasculature of the dermis to

789 avoid bleeding (Schubert \& Christophers 1985). This process is thus completely different from

790 the normal skin shedding of squamate reptiles, which leads to a loss of keratinized epidermis

791 only (Schubert \& Christophers 1985). The scarless regeneration of the whole integument occurs

792 within a few weeks, apparently starting from stem cells of the deeper layers of the connecting

793 tissue and is considered as unique among vertebrates (Schubert et al. 1990). Superficially, no

794 differences are apparent between regenerated and original scales, due to the irregularity of

795 scalation patterns and some variability in scale size. The same is true for regenerated tails;

796 indeed, it is often hard to be certain that a Geckolepis tail has been regenerated without X-ray

797 images showing that the vertebrae are absent.

798 The new species is remarkable in the possession of proportionally larger scales than any of its 799 congeners (especially in the dorsal cervical region, see Figs 3 and 4). Midbody dorsal scales of

800 Geckolepis megalepis are 7.3-8.3\% of the SVL (by comparison, a typical midbody dorsal scale

801 of the holotype of G. maculata is just 5.4\% of its SVL). Indeed, G. megalepis may have the

802 largest mid-body scales of any gecko in both relative and absolute terms, as its scales outstrip

803 those of all known congeners, and only Teratoscincus may approach Geckolepis in scale size.

804 Remarkably, the latter genus has similarly fragile skin (Bauer et al. 1993), which may have

805 evolved for similar antipredatory function.

806 The exceptionally large scales of G. megalepis lead to questions about the possible advantage

807 of larger scales for species with autotomizable integument. As is visible in Fig. 3C, the large,

808 imbricate body scales of Geckolepis megalepis are attached to the integument only superficially

809 by a narrow transparent zone which covers less than $20 \%$ of the scale's edge surface. Schmidt

810 (1911) called this region the 'Anwachsfläche' (literally 'attachment area'), and noted that it is 
811 much smaller relative to the size of the scales of Geckolepis than in other lizards. With

812 increasing scale diameter, the circumference of the scale and therefore its zone of connectivity

813 increases linearly while the area of the scales increases exponentially (approximating the scales

814 to a circular shape). This increases the surface area and therefore force of friction on scales

815 exponentially while the 'tear zone' of the scales increases linearly, meaning that there is a

816 smaller tear zone per unit area with greater scale size. Thus, less force, applied in a posterior or

817 lateral direction, should be required to remove a larger scale than a smaller one. Additionally, as

818 the scales are imbricate, leverage may play a role: an anteriorly directed pressure on the scales

819 may cause them to lift and detach, much as one might detach a sticky note from a surface. The

820 leverage of a longer scale is greater than a shorter one, and these may therefore lift more easily.

821 This is probably further enhanced by the steeper angle of larger scales to the body (Schmidt

822 1911). Together, these principles may explain why the scales of G. megalepis appear to come off

823 more easily than those of other Geckolepis species, but further studies are clearly necessary to

824 confirm or reject this hypothesis.

825 Although it is highly plausible to interpret their ability of scale autotomy as an anti-predator

826 defence mechanism, direct observations of predation events or attempts on Geckolepis

827 individuals are scarce and include only a scorpion (Grosphus flavopiceus), a bird (Dicrurus

828 forficatus) and a large nocturnal Blaesodactylus gecko (Gardner \& Jasper 2014, 2015; Glaw et

829 al. 2002). In the lattermost case, the Geckolepis individual slipped from the mouth of the

830 Blaesodactylus ca. 30 seconds after being captured, and escaped denuded (Gardner \& Jasper

831 2015), thereby providing the first direct evidence of successful escape by skin shedding. Further

832 studies on the role of dermolytic scale autotomy by Geckolepis are clearly needed, in order to

833 understand its functionality with a range of predators (its function against snakes, for instance,

834 has not yet been observed), and to understand the pressures driving the evolution of greater scale

835 size in this particular lineage of Geckolepis.

\section{The osteology of Geckolepis and the next steps in resolving their taxonomy}

837 Our osteological description of the genus Geckolepis, based on six specimens of four species,

838 reveals strong morphological conservatism in this genus. Few characters show potentially

839 diagnostic differences at the species level (see Appendix 2), and the degree of intra-specific

840 variation is apparently quite high. However, through the use of micro-CT, we were able to

841 include the holotype of G. maculata in our skeletal description. This will be an important step 
842 toward the resolution of its identity, despite our continued failure to trace its type locality (see

843 supplementary information). Lemme et al. (2013) assigned their OTU AB to this species on the

844 basis of its overall similar morphology, but our analysis of their skulls suggests that they are

845 probably not conspecific. This means that the assignment of this name is still completely

846 unknown; it belongs either to another of the known clades, or to one not yet characterised. A

847 broader survey of the osteology of the genus will be required to resolve the identity of this

848 species, and will in turn yield the total resolution of this genus.

849 Despite the detailed osteological description, we admit that Geckolepis represents an

850 extremely difficult taxonomic group that is hard to characterise. The high variability in scale

851 number and enhanced ability to shed scales upon capture has misled taxonomists in the past into

852 believing they were dealing with distinct new species, which have subsequently been

853 synonymised (Angel 1942; Köhler et al. 2009). The trouble is further enhanced by multiple

854 genetic lineages occurring in sympatry (Lemme et al. 2013; Fig. 1), and further still by apparent

855 osteological conservatism. However, we were able to show that this is not always the case, and

856 members of the AB OTU of Lemme et al. (2013) for instance show strong osteological

857 differences that will facilitate its description. Nevertheless, the osteology did not provide as

858 many taxonomic characters as we had hoped. Admittedly our sample size is small, and therefore

859 practically no data yet exist on the degree of inter- and intraspecific osteological variation in

860 these geckos. Examination of many further specimens and other lineages will enhance our ability

861 to use osteology as a source of characters in their taxonomic resolution.

862 Thus, the next steps are now clear: (1) a survey of osteology in this genus in the context of

863 molecular phylogenetic relationships of OTUs, and (2) a survey of intraspecific and sexual

864 skeletal variability in at least one lineage, although this is generally minimal among gekkotans

865 (Daza et al. 2009). Based on this data and corresponding other datasets, we must establish with a

866 high degree of certainty which OTU from Lemme et al. (2013) really corresponds to G. maculata

867 (if any). Once this information is gathered, we may proceed with the resolution of the taxonomy

868 of the genus.

869 The framework of an integrative dataset composed of morphological, meristic, molecular

870 phylogenetic, and osteological data has considerable potential for dealing with species

871 complexes in squamates - even those as tortuous as Geckolepis, and certainly in other species

872 with fragile skin. However, it is clear that the robustness of conclusions strongly depends on the 
873 available sample size. In instances, such as this one, where sample size is limited to a low

874 number of specimens, any osteological, morphological, or pholidotic feature identified as

875 differing must first be highlighted as being potentially diagnostic, until more data becomes

876 available to verify the value of each of these features. Nevertheless, the value of these data,

877 especially when they are extracted from holotypes and old specimens in a non-destructive way,

878 cannot be overstated. Micro-CT is therefore likely to have a pivotal role in resolving many

879 difficult species complexes.

880

\section{ACKNOWLEDGEMENTS}

882 We thank the Malagasy authorities for issuing collection and export permits. Thanks are also due 883 to O. Hawlitschek, E. Z. Lattenkamp, H. Rösler and C. Y. Wang-Claypool for their support and 884 help. P. Bora, N. D'Cruze, H. Enting, M. Franzen, K. Glaw, T. Glaw, Jaques, A. Knoll, M.

885 Puente, N. A. Raharinoro and R. Randrianiaina helped conduct fieldwork and Y. Pareik with 886 logistics and his great hospitality. We also thank N. Holovacs for his assistance with the 887 rotational videos, and M.-O. Rödel for the loan of the G. maculata holotype. We thank D. Paluh, 888 A. Griffing and A. M. Bauer for access to their manuscript on the osteoderms of Geckolepis. J.

889 Grismer and E. Stanley gave helpful suggestions for the improvement of this article, and we are 890 grateful to them.

891

892

\section{REFERENCES}

893

894

Angel F. 1942. Les lézards de Madagascar. Memoires de l'Académie Malgache 36:1-139.

895 Arnold EN. 1984. Evolutionary aspects of tail shedding in lizards and their relatives. Journal of

896

897

898

899

900

901

902

903

904

905

906

907

908

909 Natural History 18:127-169.

Bateman PW, and Fleming PA. 2009. To cut a long tail short: a review of lizard caudal autotomy studies carried out over the last 20 years. Journal of Zoology 277:1-14.

Bauer AM, and Russell AP. 1989. Supraorbital ossifications in geckos (Reptilia: Gekkonidae). Canadian Journal of Zoology 67:678-684.

Bauer AM, Russell AP, and Shadwick RE. 1993. Skin mechanics and morphology of the gecko Teratoscincus scincus. Amphibia-Reptilia 14:321-331.

Daza JD, Abdala V, Thomas R, and Bauer AM. 2008. Skull anatomy of the miniaturized gecko Sphaerodactylus roosevelti (Squamata: Gekkota). Journal of Morphology 269:13401364.

Daza JD, and Bauer AM. 2015. Cranial anatomy of the pygopodid lizard Aprasia repens, a gekkotan masquerading as a Scolecophidian. In: Bininda-Emonds ORP, Powell GL, Jamniczky HA, Bauer AM, and Theodor J, eds. All animals are interesting: A festschrift in honour of Anthony P Russell. Oldenburg, Germany: BIS-Verlag, 399-405. 
910 Daza JD, Bauer AM, and Snively ED. 2013. Gobekko cretacicus (Reptilia: Squamata) and its

911

912

913

914

915

916

917

918

919

920

921

922

923

924

925

926

927

928

929

930

931

932

933

934

935

936

937

938

939

940

941

942

943

944

945

946

947

948

949

950

951

952

953

954

955 bearing on the interpretation of gekkotan affinities. Zoological Journal of the Linnean Society 167:430-448.

Daza JD, Herrera A, Thomas R, and Claudio H. 2009. Are you what you eat? A geometric morphometric analysis of gekkotan skull shape. Biological Journal of the Linnean Society 97:677-707.

Evans SE. 2008. The skull of lizards and tuatara. In: Gaunt AS, and Adler K, eds. The Skull of Lepidosauria. Ithaca, NY, USA: Society for the Study of Amphibians and Reptiles, 1348.

Gardner CJ, and Jasper L. 2014. A record of vertebrate carnivory by the Crested Drongo (Dicrurus forficatus). Malagasy Nature 8:105-106.

Gardner CJ, and Jasper L. 2015. A fish-scaled gecko (Geckolepis sp.) escapes predation by a velvet gecko (Blaesodactylus sp.) through skin shedding. Herpetology Notes 8:479-481.

Glaw F, Gehring P-S, Köhler J, Franzen M, and Vences M. 2010. A new dwarf species of day gecko, genus Phelsuma, from the Ankarana pinnacle karst in northern Madagascar. Salamandra 46:83-92.

Glaw F, Köhler J, Townsend TM, and Vences M. 2012. Rivaling the world's smallest reptiles: discovery of miniaturized and microendemic new species of leaf chameleons (Brookesia) from northern Madagascar. PLoS One 7:e31314. 10.1371/journal.pone.0031314

Glaw F, and Vences M. 2007. A Field Guide to the Amphibians and Reptiles of Madagascar. Köln, Germany: Vences \& Glaw Verlags GbR.

Glaw F, Vences M, and Lourenco WR. 2002. Geckolepis maculata (Spotted Fishscale Gecko) Predation. Herpetological Review 33:135.

Hawkins AFA, Chapman P, Ganzhorn JU, Bloxam QMC, Barlow SC, and Tongue SJ. 1990. Vertebrate conservation in Ankarana Special Reserve, northern Madagascar. Biological Conservation 43:83-110.

Hawlitschek O, Scherz MD, Straube N, and Glaw F. 2016. Resurrection of the Comoran fish scale gecko Geckolepis humbloti Vaillant, 1887 reveals a disjointed distribution caused by natural overseas dispersal. Organisms Diversity \& Evolution 16:289-298. 10.1007/s13127-015-0255-1

Jono T, Bauer AM, Brennan I, and Mori A. 2015. New species of Blaesodactylus (Squamata: Gekkonidae) from Tsingy karstic outcrops in Ankarana National Park, northern Madagascar. Zootaxa 3980:406-416.

Kluge AG. 1967. Higher taxonomic categories of gekkonid lizards and their evolution. Bulletin of the American Museum of Natural History 135:1-60.

Köhler G, Diethert H-H, Nussbaum RA, and Raxworthy CJ. 2009. A revision of the fish scale geckos, genus Geckolepis Grandidier (Squamata, Gekkonidae) from Madagascar and the Comoros. Herpetologica 65:419-435.

Lécuru S. 1968. Remarques sur le scapulo-coracoïde des lacertiliens. Annales des Sciences Naturelles-Zoologie et Biologie Animale 12:475-510.

Lemme I, Erbacher M, Kaffenberger N, Vences M, and Köhler J. 2013. Molecules and morphology suggest cryptic species diversity and an overall complex taxonomy of fish scale geckos, genus Geckolepis. Organisms Diversity \& Evolution 13:87-95. 10.1007/s13127-012-0098-y

Payne S, Holliday CM, and Vickaryous MK. 2011. An osteological and histological investigation of cranial joints in geckos. The Anatomical Record 294:399-405. 
956 Rieppel O. 1984. The structure of the skull and jaw adductor musculature of the Gekkota, with

957

958

959

960

961

962

963

964

965

966

967

968

969

970

971

972

973

974

975

976

977

978

979

980

981

982

983

984

985

986

987

988

989

990

991

992 comments on the phylogenetic relationships of the Xantusiidae (Reptilia: Lacertilia). Zoological Journal of the Linnean Society 82:291-318.

Romer AS. 1956. The Osteology of the Reptiles. Chicago IL, USA: The University of Chicago Press.

Ruane S, Burbrink FT, Randriamahatantsoa B, and Raxworthy CJ. 2016. The cat-eyed snakes of Madagascar: Phylogeny and description of a new species of Madagascarophis (Serpentes: Lamprophiidae) from the Tsingy of Ankarana. Copeia 104:712-721.

Russell AP, and Bauer AM. 2008. The appendicular locomotor apparatus of Sphenodon and normal-limbed squamates. In: Gans C, Gaunt AS, and Adler K, eds. The Skull and Appendicular Locomotor Apparatus of Lepidosauria. Ithaca NY, USA: Society for the Study of Amphibians and Reptiles, 1-465.

Russell AP, Vickaryous MK, and Bauer AM. 2016. The phylogenetic distribution, anatomy and histology of the post-cloacal bones and adnexa of geckos. Journal of Morphology 277:264-277. 10.1002/jmor.20494

Scherz MD, Hawlitschek O, Andreone F, Rakotoarison A, Vences M, and Glaw F. in review. A review of the taxonomy and osteology of the Rhombophryne serratopalpebrosa-group (Anura: Microhylidae) from Madagascar, with comments on the value of volume rendering of micro-CT data to the modern taxonomist. Zootaxa.

Schmidt WJ. 1911. Beobachtungen an der Haut von Geckolepis und einigen anderen Geckoniden. In: Voeltzkow A, ed. Reise in Ostafrika in den Jahren 1903-1905 mit Mitteln der Hermann und Elise geb. Heckmann Wentzel-Stiftung ausgeführt: Wissenschaftliche Ergebnisse von Alfred Voeltzkow. Stuttgart: Schweizerbart'sche Verlagsbuchhandlung, 331-352.

Schubert C, and Christophers E. 1985. "Dermolytische Schreckhäutung" - ein besonderes Autotomieverhalten von Geckolepis typica (Reptilia, Gekkonidae). Zoologischer Anzeiger 214:129-141.

Schubert C, Steffen T, and Christophers E. 1990. Weitere Beobachtungen zur "dermolytischen Schreckhäutung" bei Geckolepis typica (Reptilia, Gekkonidae). Zoologischer Anzeiger 224:175-192.

Vickaryous MK, Meldrum G, and Russell AP. 2015. Armored geckos: A histological investigation of osteoderm development in Tarentola (Phyllodactylidae) and Gekko (Gekkonidae) with comments on their regeneration and inferred function. Journal of Morphology 276:1345-1357. 10.1002/jmor.20422

Voeltzkow A. 1893. Tägliches Leben eines Sammlers und Forschers auf Exkursionen in den Tropen. Bericht über die Senckenbergische Naturforschende Gesellschaft in Frankfurt am Main:43-50. 


\section{Table $\mathbf{1}$ (on next page)}

Comparative morphological data on Geckolepis megalepis, the holotype of G. maculata (ZMB 9655), with values for G. polylepis and G. typica given by Köhler et al. (2009).

Note: ranges for $G$. polylepis are probably reliable, but those for $G$. typica certainly come from several OTUs, and are therefore not actually representative of the variation of that species. Values for true G. typica, as for G. maculata, are currently certain only from its holotype. 
1 Table 1. Comparative morphological data on Geckolepis megalepis, the holotype of G.

2 maculata (ZMB 9655), with values for G. polylepis and G. typica given by Köhler et al. (2009).

3 Note: ranges for G. polylepis are probably reliable, but those for G. typica certainly come from

4 several OTUs, and are therefore not actually representative of the variation of that species.

5 Values for true G. typica, as for G. maculata, are currently certain only from its holotype.

\begin{tabular}{|c|c|c|c|c|}
\hline Species: & G. megalepis sp. nov. & G. maculata & G. polylepis & G. typica \\
\hline No. Specimens & 3 & Only ZMB 9655 & 11 & 102 \\
\hline SVL (mm) & $57.8-69.5(65.2 \pm 6.46)$ & 58.5 & $41.1-50.2(46.5 \pm 2.8)$ & $31.1-56.3(43.0 \pm 5.02)$ \\
\hline $\mathrm{TL}(\mathrm{mm})$ & $71.7-80.1(75.3 \pm 4.33)$ & N/A & $34.5-56.5(48.0 \pm 6.4)$ & $29.7-58.5(43.6 \pm 6.83)$ \\
\hline $\mathrm{Ax}-\mathrm{Gr}(\mathrm{mm})$ & $23.9-32.5(27.9 \pm 4.34)$ & 23.7 & $14.7-24.3(19.8 \pm 2.7)$ & $12.4-28.3(19.0 \pm 2.76)$ \\
\hline $\operatorname{ShL}(\mathrm{mm})$ & $5.0-7.0(5.9 \pm 1.01)$ & 6.2 & $5.5-7.2(6.5 \pm 0.5)$ & $4.0-8.2(5.7 \pm 0.72)$ \\
\hline HL (mm) & $14.9-17.1(16.0 \pm 1.10)$ & 15.2 & $9.7-12.0(10.7 \pm 0.8)$ & $6.9-12.8(9.6 \pm 1.08)$ \\
\hline HW (mm) & $13.3-18.5(16.0 \pm 2.60)$ & 14.2 & $9.1-12.0(10.6 \pm 0.9)$ & $6.4-14.2(9.8 \pm 1.43)$ \\
\hline $\mathrm{HH}(\mathrm{mm})$ & $7.4-10.1(8.80 \pm 1.35)$ & 7.6 & $4.8-6.4(5.8 \pm 0.5)$ & $3.4-8.8(5.1 \pm 0.77)$ \\
\hline $\mathrm{SnL}(\mathrm{mm})$ & $7.0-7.9(7.5 \pm 0.47)$ & 7.0 & $4.8-5.8(5.1 \pm 0.3)$ & $3.2-6.0(4.4 \pm 0.54)$ \\
\hline $\mathrm{ED}(\mathrm{mm})$ & $4.3-4.3(4.3 \pm 0.00)$ & 3.7 & $2.2-3.3(2.6 \pm 0.3)$ & $1.8-3.2(2.4 \pm 0.29)$ \\
\hline IOD (mm) & $7.7-9.6(8.7 \pm 0.95)$ & 7.0 & $4.6-6.4(5.3 \pm 0.5)$ & $3.5-6.7(4.9 \pm 0.64)$ \\
\hline $\mathrm{EED}(\mathrm{mm})$ & $4.9-6.3(5.4 \pm 0.78)$ & 4.8 & $2.8-4.0(3.4 \pm 0.4)$ & $2.2-4.1(3.1 \pm 0.41)$ \\
\hline IOS & $9-10(9.67 \pm 0.58)$ & 9 & $9-12(10.8 \pm 1.09)$ & $9-13(10.6 \pm 0.93)$ \\
\hline SPL & $7-8(7.33 \pm 0.52)$ & 6 & $6.0-7.0(6.91 \pm 0.30)$ & $5.0-7.0(6.06 \pm 0.44)$ \\
\hline IFL & $4.5-4.8(4.6 \pm 0.15)^{*}$ & 4.1 & $4.0-5.5(4.65 \pm 0.45)$ & $2.8-4.6(3.72 \pm 0.39)$ \\
\hline $\mathrm{CS}$ & $6-7(6.7 \pm 0.58)$ & 6 & $6-7(6.1 \pm 0.30)$ & $4-7(5.5 \pm 0.58)$ \\
\hline MBS & $17-18(17.7 \pm 0.58)$ & 25 & $30-37(34.5 \pm 2.46)$ & $26-36(30.9 \pm 1.98)$ \\
\hline VS & $27-31(29.0 \pm 2.00)$ & 32 & $40-50(44.6 \pm 3.01)$ & $37-48(41.6 \pm 0.22)$ \\
\hline VHL & $6.0-8.0(7.0 \pm 1.00)$ & 9 & $7.0-13.0(10.41 \pm 1.76)$ & $7.0-12.0(8.78 \pm 1.11)$ \\
\hline L1TT & $14-15(14.33 \pm 0.58)$ & 12 & $8-15(10.4 \pm 1.86)$ & $8-13(9.6 \pm 1.03)$ \\
\hline L4TT & $18-21(19.67 \pm 1.53)$ & 17 & $10-18(15.3 \pm 2.31)$ & $11-18(14.9 \pm 1.09)$ \\
\hline SAE/SPE & $0.42-0.48(0.45 \pm 0.03)$ & 0.49 & $0.67-1.00(0.79 \pm 0.01)$ & $0.50-0.80(0.63 \pm 0.07)$ \\
\hline
\end{tabular}

6 *This value includes the specimen figured in Fig. 1A and 2A, and has a sample size of 4 . 


\section{Figure 1 (on next page)}

Molecular phylogeny and distribution of Geckolepis OTUs based mainly on Lemme et al. 2013.

Dotted lines in the phylogeny indicate uncertain placement. The phylogenetic position and distribution of Geckolepis humbloti is inferred from Hawlitschek et al. 2016. 


\section{Figure 2}

Schematic drawings exemplifying morphological measurements and scale counts, following the scheme of Hawlitschek et al. (2016) based on Köhler et al. (2009).

(A) Measurements and pholidosis of the head, drawn from the specimen in Fig. 2A (small scales around the eye and nostril not depicted); (B) body measurements; (C) postmental scale conditions, adapted from Lemme et al. (2013); (D) postnasal scale configuration types, adapted from Köhler et al. (2009). Scale counts: purple = CS; blue = SPL; red = IFL. For abbreviations and unillustrated characters, see Materials and Methods. 

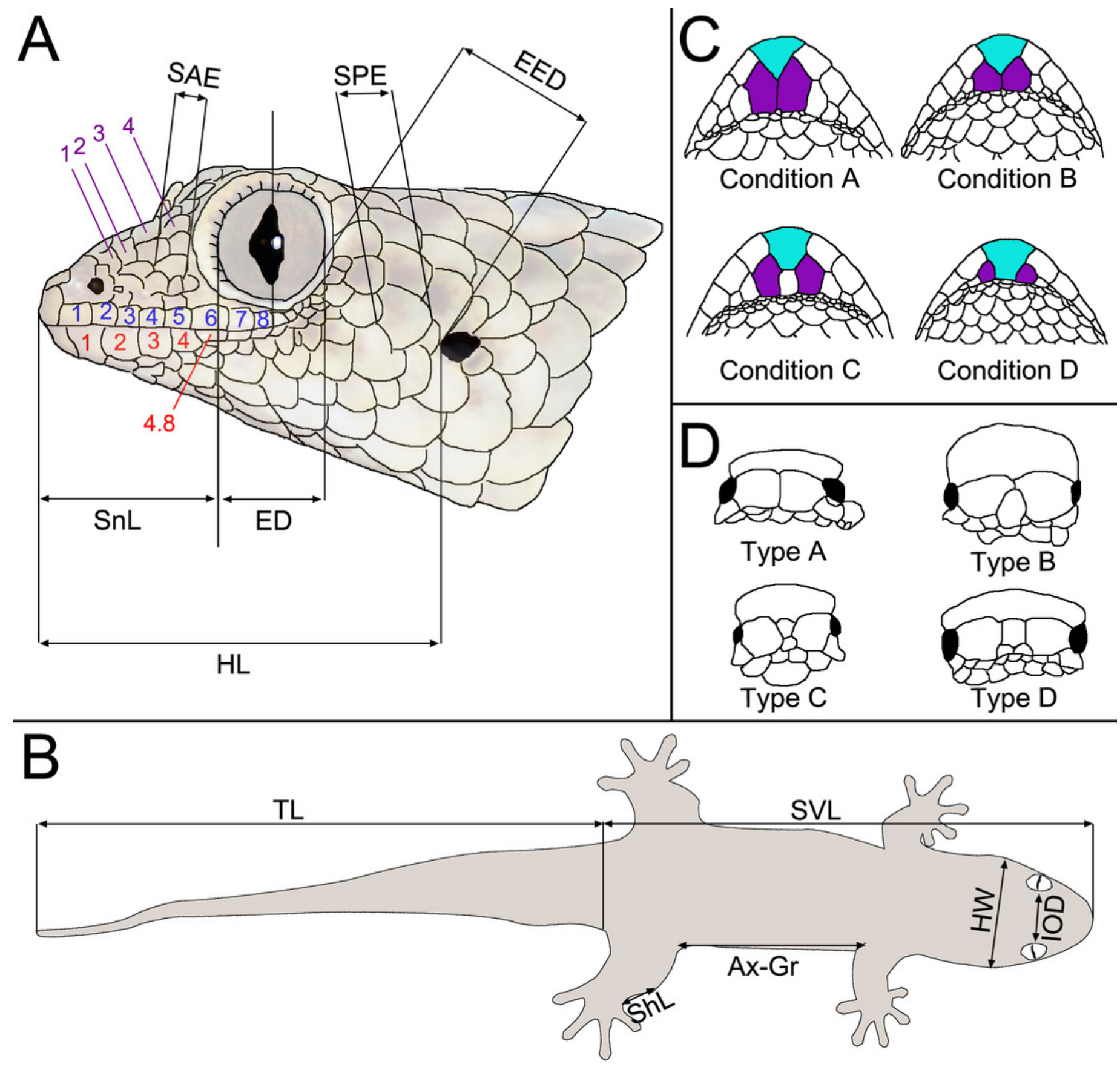


\section{Figure 3}

Specimens of Geckolepis megalepis sp. nov. in life.

(A) A specimen observed by A. Anker (photograph used with permission); (B) a specimen observed by FG, and $(C)$ a specimen photographed after scale loss, with inset indicating the transparent 'tear zone' at the base of a scale. None of the photographed animals were collected, but their attribution to G. megalepis is clear on the basis of the large size of their scales. Note that the tails of all three specimens are regenerated.

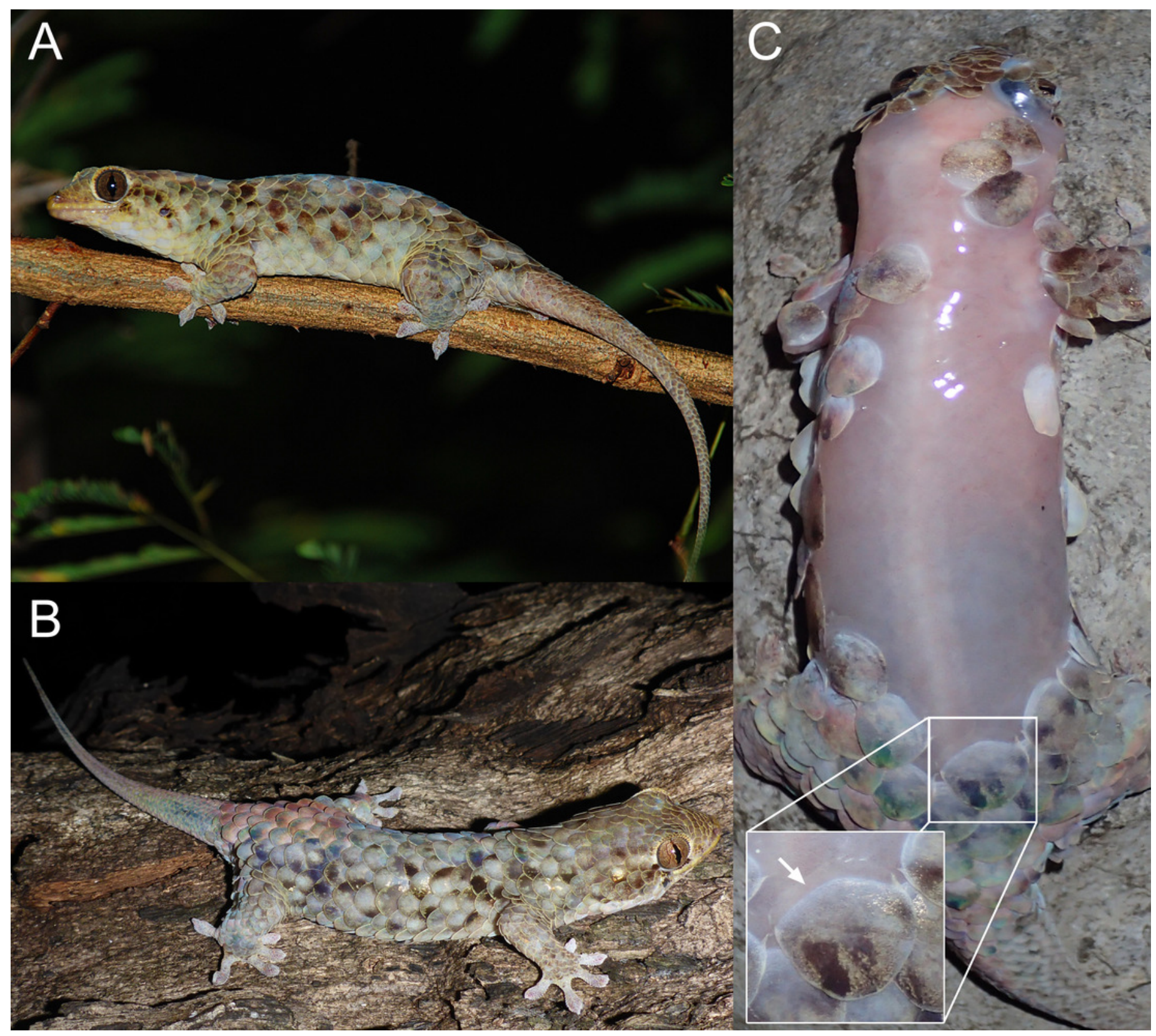




\section{Figure 4}

Specimens of Geckolepis megalepis sp. nov. in preservative.

(A-C) The holotype, ZSM 2126/2007; (D-F) paratype ZSM 232/2016. Shown in dorsal (A, D) and ventral $(C, F)$ view, with a close-up view of the postmental scales (B, E) coloured for reference to Fig. 1. Scale bars indicate $10 \mathrm{~mm}$. Chin insets are not to scale. 

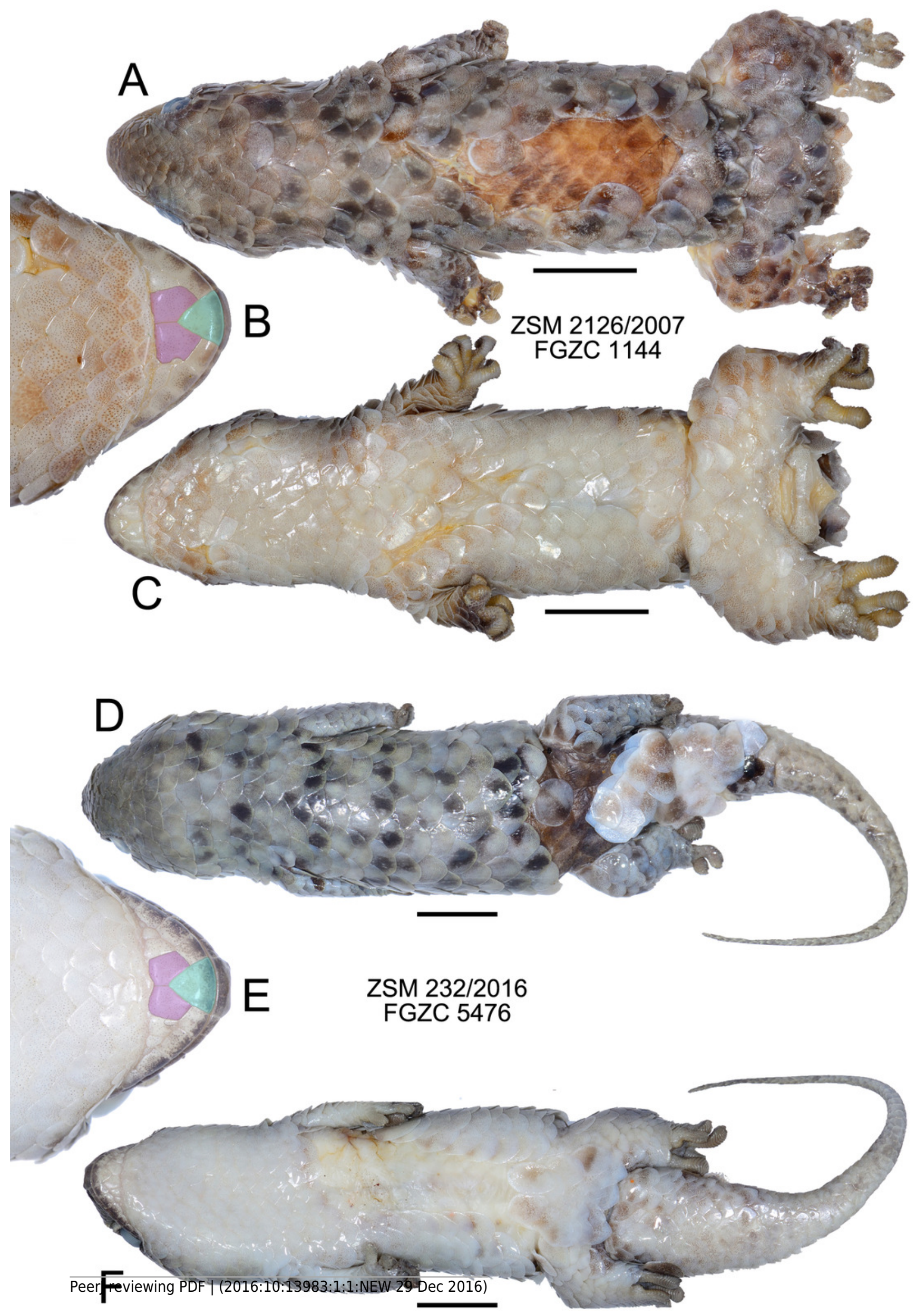


\section{Figure 5}

Micro-CT images of mineralized scales of Geckolepis specimens.

Shown in dorsal $(A, D, F, H, J)$ and ventral $(B, E, G, I, K)$ view, and coronal cut at the parietal level (C) of Geckolepis megalepis (A-C, ZSM 2126/2007), Geckolepis Clade AB (D-E, ZSM 1520/2008), G. maculata (F-G, ZMB 9655), and G. humbloti (H-I, ZSM 80/2010; J-K, ZSM 81/2006). Note the high density of the scale covering in all the species, and the lack of mineralization in the postmental scales (compare with Figs 2 and 3).
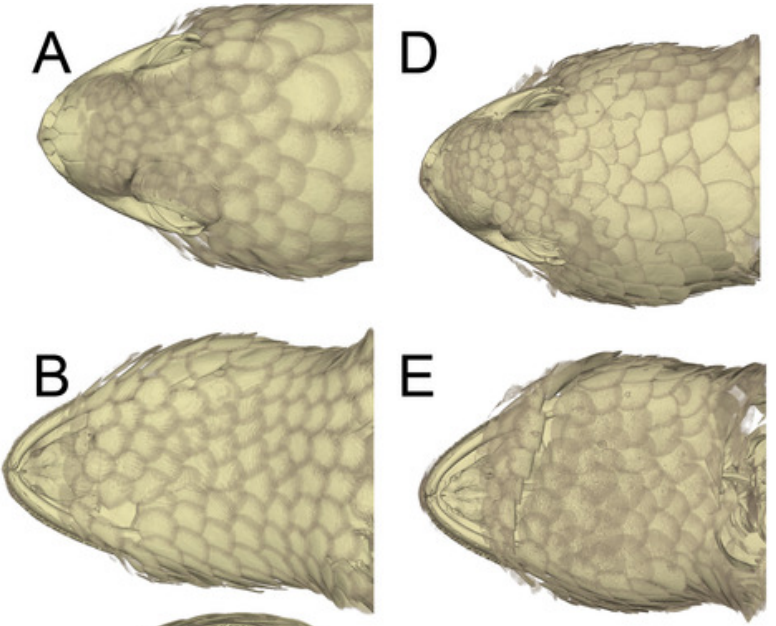

$\mathrm{F}$
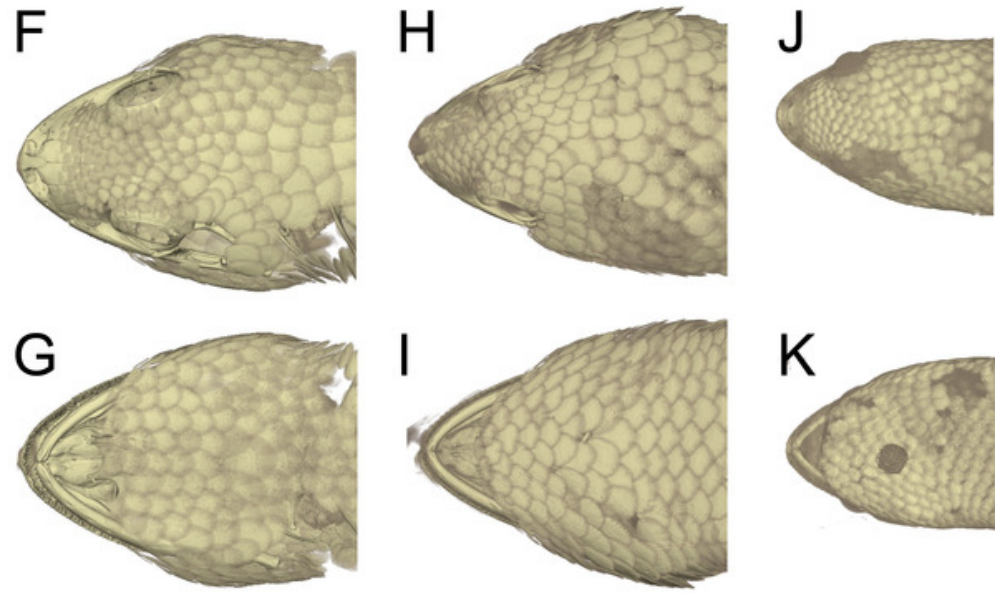

C

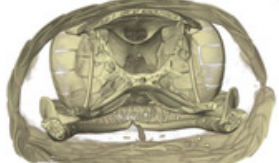




\section{Figure 6}

Micro-CT images of skull (cranium and jaw) of the holotype of Geckolepis megalepis sp. nov. (ZSM 2126/2007).

(A) Dorsal, (B) ventral, (C) lateral, (D) labial, and (E) lingual view. Abbreviations: adf, anterior inferior dental foramen; amf, anterior mylohyoid foramen; ar, articular facet; asnp, ascending nasal process of premaxilla; bo, basioccipital; $b p$, basipterygoid process of parabasisphenoid; $c h$, choana; cob, compound bone; cor, coronoid; $d$, dentary; $d p p$, descending parietal process; ect, ectopterygoid; ept, epipterygoid; $f$, frontal; $h s c c$, horizontal semi-circular canal; if, incisive foramen; $j$, jugal; larst, lateral aperture of the recessus scalae tympani; $m f$, mental foramen; mko, opening of the Meckelian canal, $m x$, maxilla; $m x$.ap, anterior process of maxilla; $m x . f p$, facial process of maxilla; $m x . p p$, posterior process of maxilla; $n$, nasal; occ, occipital condyle; oto, otooccipital; pal, palatine; pal.mp, maxillary process of palatine; par, parietal; pbsh, parabasiphenoid; $p m x$, premaxilla; $p m x . p p s$, premaxilla palatal shelf; pof, postorbitofrontal; pop, paroccipital process; ppp, posterolateral process of parietal; prf, prefrontal; pro, prootic; pro.ca, crista alaris of prootic; pro.cp, crista prootica of prootic; psaf, posterior surangular foramen; $p s c c$, posterior semicircular canal; $p t$, pterygoid; $p t . q p$, quadrate process of pterygoid; $q$, quadrate; $q$.ch, conch of quadrate; rap, retroarticular process; s, stapes; saf, surangular foramen; scr, sclerotic ring; $s m x$, septomaxilla; spl, splenial; sof, suborbital fenestra; sq, squamosal, pscc, posterior semicircular canal; so, supraoccipital; spht, sphenooccipital tubercle; tbr, trabeculae; $v$, vomer; v.lp, lateral process of vomer. A rotational video of the skull is provided in the supplementary materials (SV1). 

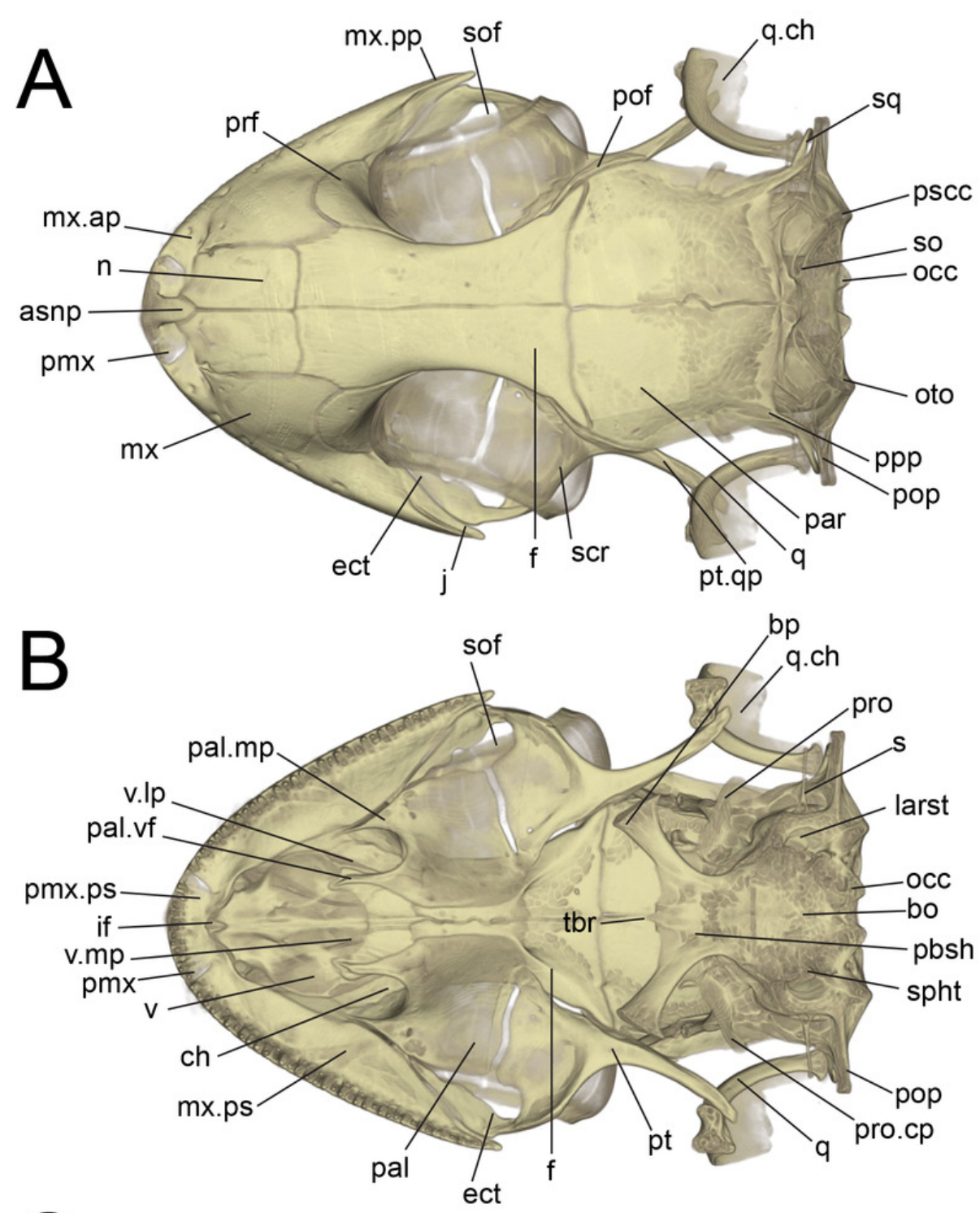

C

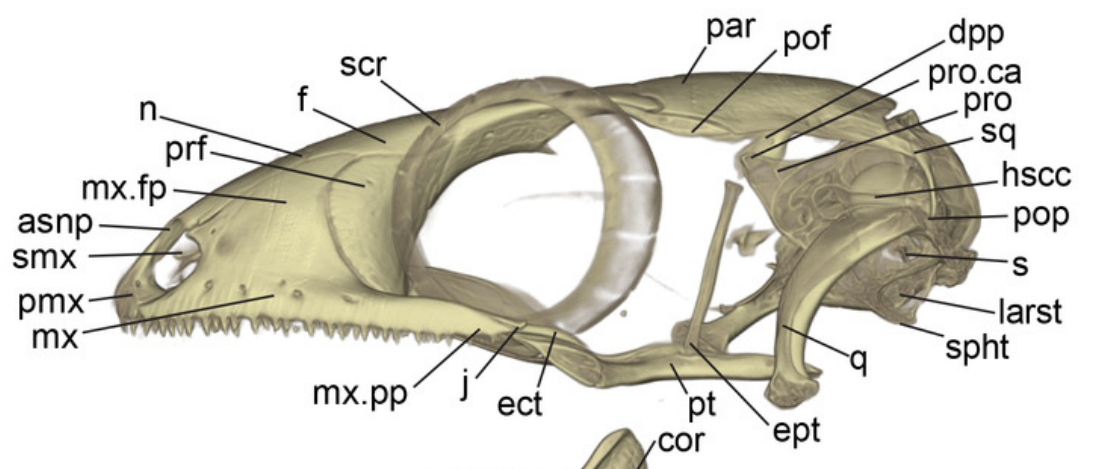

D
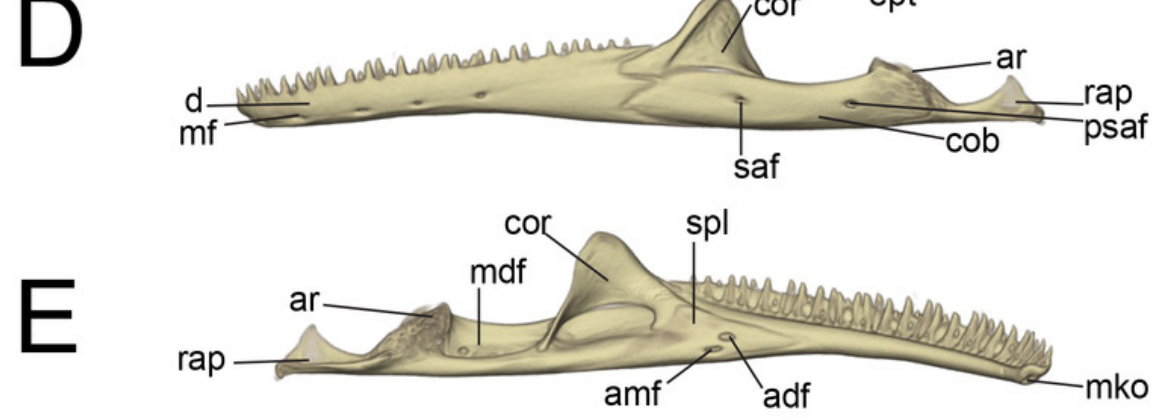


\section{Figure 7}

Comparative micro-CT images of the skull (cranium and jaw) of other Geckolepis species.

Shown in dorsal $(A, F, K, P)$, ventral $(B, G, L, Q)$, lateral $(C, H, M, R)$, labial $(D, I, N, S)$, and lingual $(E, J, O, T)$ view. Depicting Geckolepis Clade AB (A-E, ZSM 1520/2008), holotype of G. maculata (F-J, ZMB 9655), and G. humbloti (K-O, ZSM 80/2010; P-T, ZSM 81/2006). From volume-rendering of micro-CT scans. Rotational videos of these skulls are provided in the supplemental materials (SV2-5). For labels see Fig. 5.
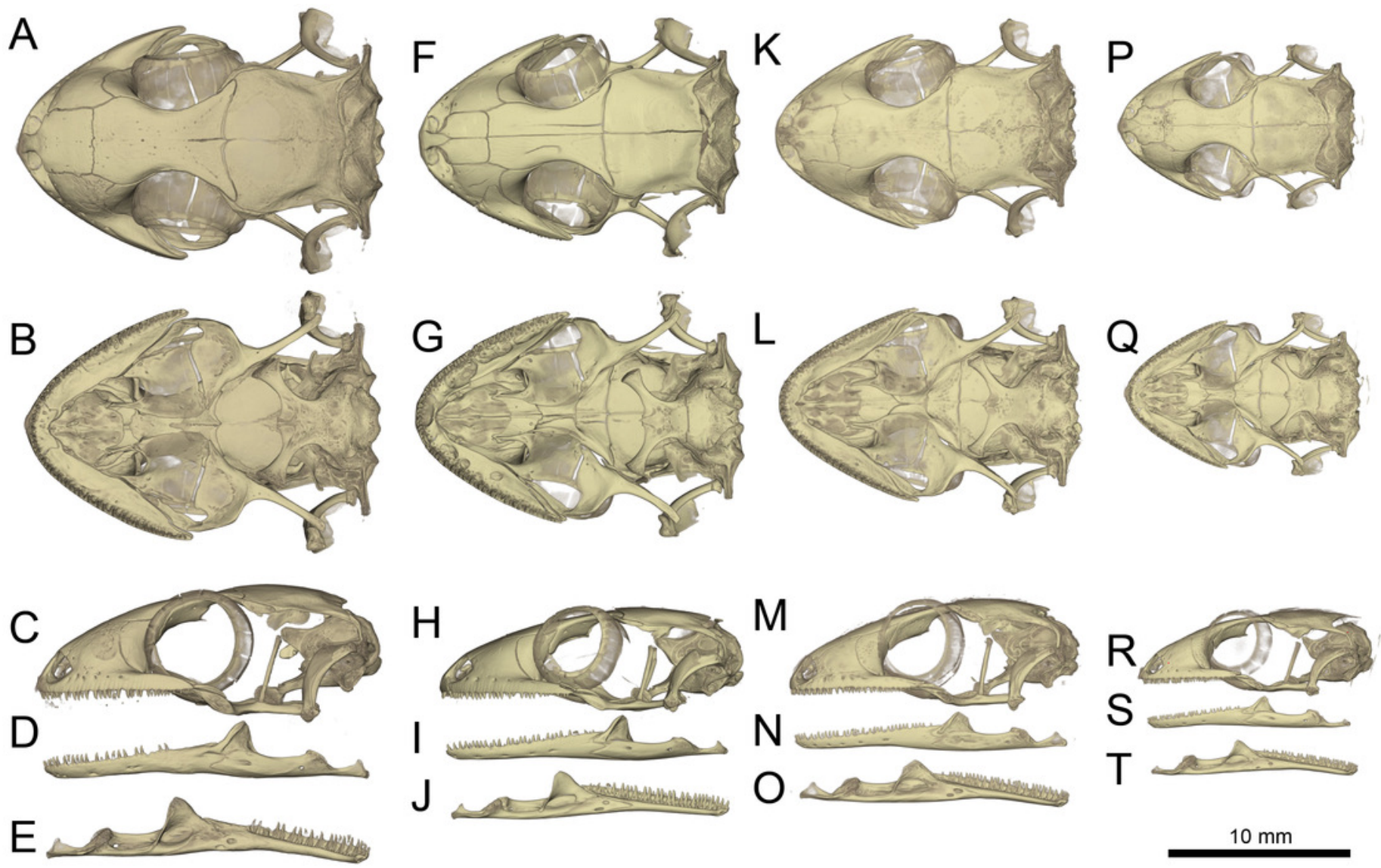


\section{Figure 8}

Micro-CT images of spinal column of Geckolepis, based on G. megalepis sp. nov. (ZSM 2126/2007).

(A) Lateral and (B) dorsal view. Abbreviations: Ib, lumbar; $s c$, sacral. Regions are indicated by the posterodorsal-most point of the neural arches. 

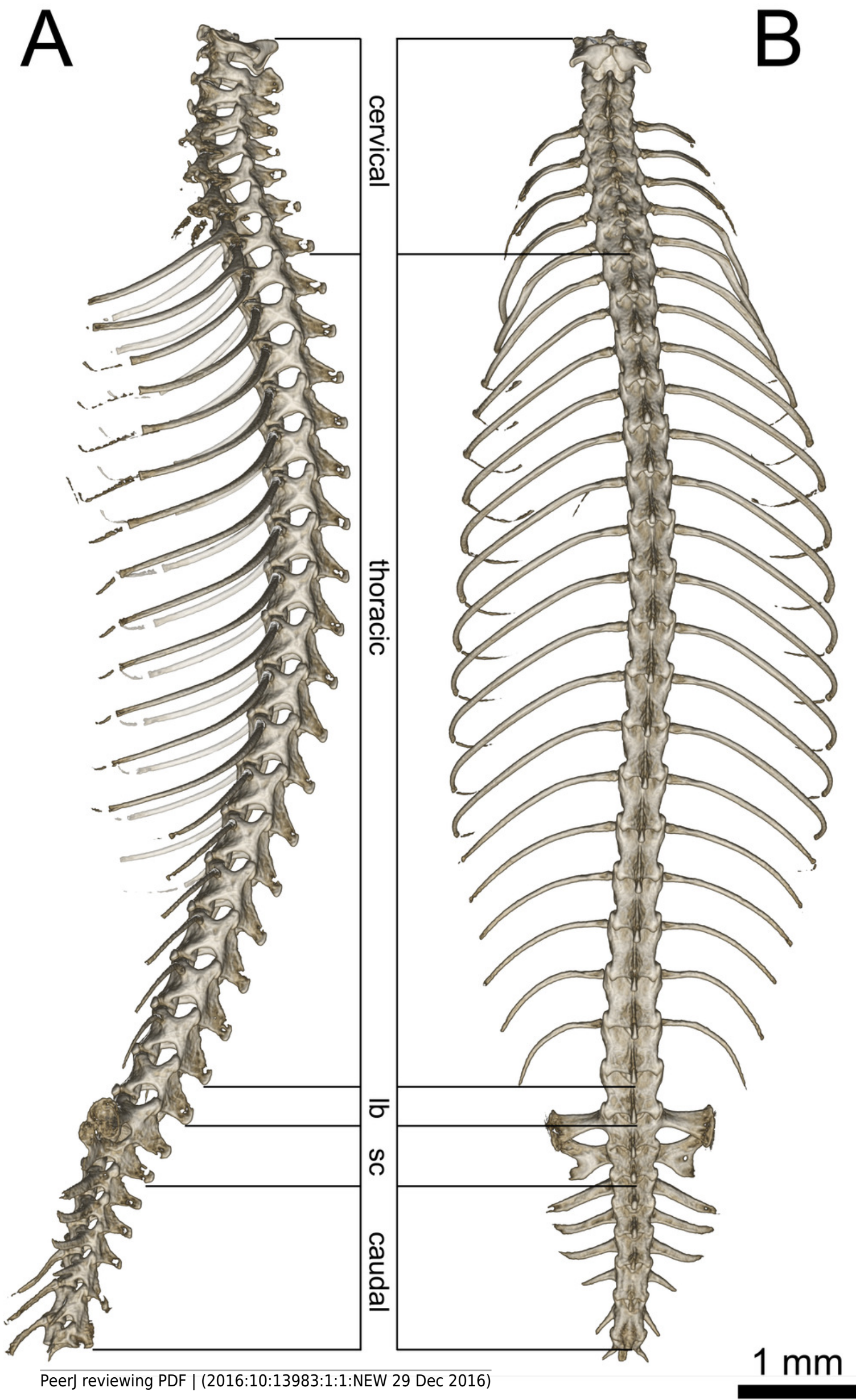


\section{Figure 9}

Micro-CT images of pectoral girdle of Geckolepis, based on G. megalepis sp. nov. (ZSM 2126/2007).

(A) Ventral and (B) lateral view. Abbreviations: 1cf, primary coracoid fenestra; $2 c f$, secondary coracoid fenestra; acr, acromion process; cf, clavicular fenestra; cl, clavicle; cor, coracoid; ic, interclavicle; $g f$, glenoid fossa; $h u$, humerus; hu.c, humeral condyle; hu.dtp, deltopectoral crest of humerus; hu.ec, ectepicondylar crest of humerus; $m c$, metacarpal; $m s$, mesosternum; $p$, phalanges; $p s$, presternum; $p u$, patella ulnaris; $r$, radius; $r l$, radiale; $s$, scapula; sc.1c, primary coracoid ray of scapulocoracoid; sc.2c, secondary coracoid ray of scapulocoracoid; scf, scapulocoracoid fenestra; sf, scapular fenestra; ss, suprascapula; sc.sr, scapular ray of scapulocoracoid; sr, sternal ribs; sucf, supracoracoid foramen; $u$, ulna; ul, ulnare; $x s$, xiphisternum. 


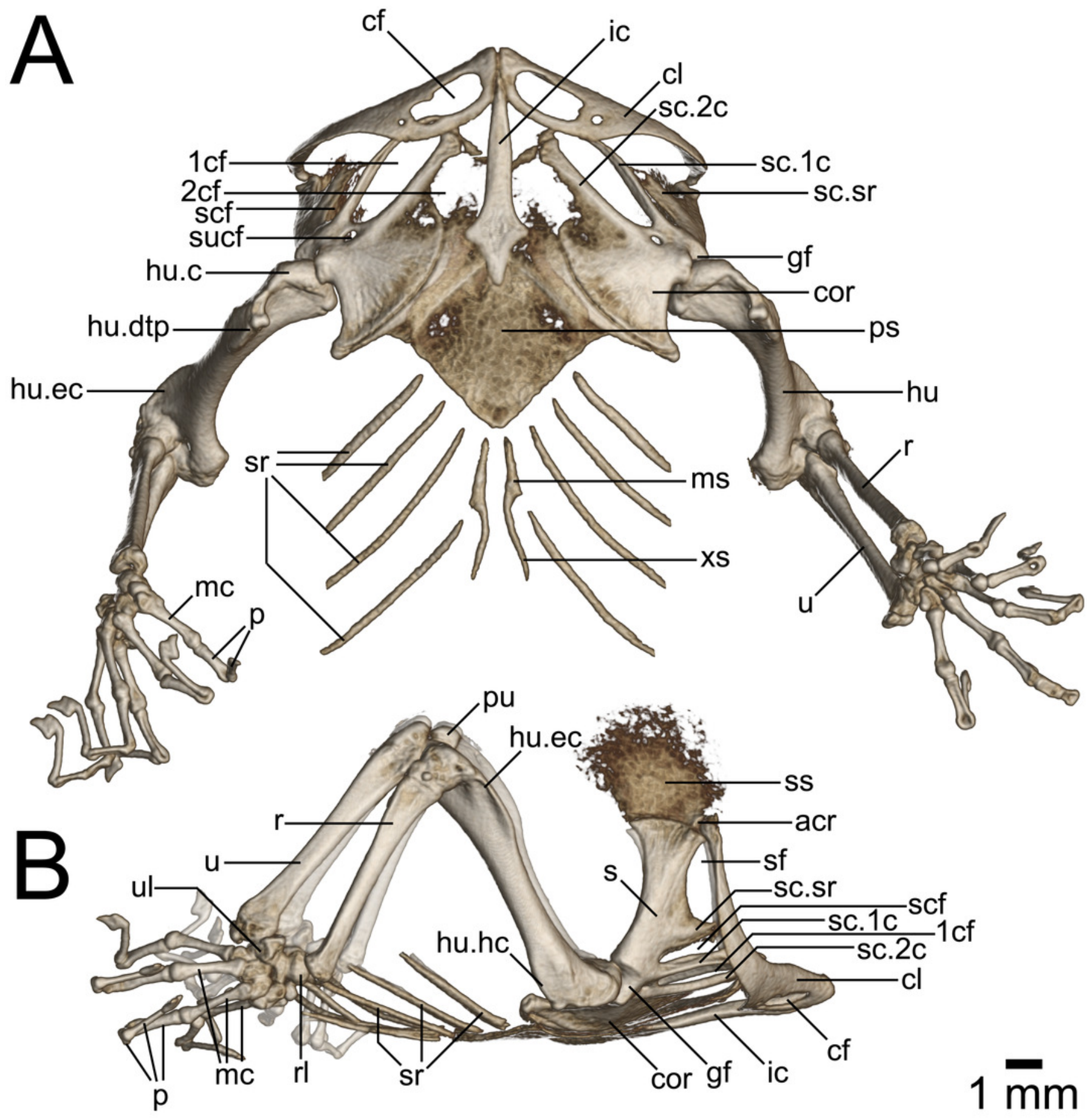




\section{Figure 10}

Micro-CT images of pelvic girdle of Geckolepis, based on G. megalepis sp. nov. (ZSM 2126/2007).

(A) Dorsal and (B) lateral view. Abbreviations: ac, acetabulum; ag, astragalocalcaneum; ep, epipubis; $f$, femur; $f b$, fibula; f.it, internal trochanter; f.itf, intertrochanteric fossa; f.fc, femoral condyle; hyi, hypoischium; il, ilium; il.pap, preacetabular process of ilium; is, ischium; is.t, ischiadic tuberosity; $m t$, metatarsals; of, obturator foramen; $p$, phalanges; pic, proischiadic cartilage; $p b$, pubis; $p b . p l$, processus lateralis of pubis; $p c$, post-cloacal bone; $p t$, pubic tubercle; tb, tibia; $t f$, thyroid fenestra. 
A
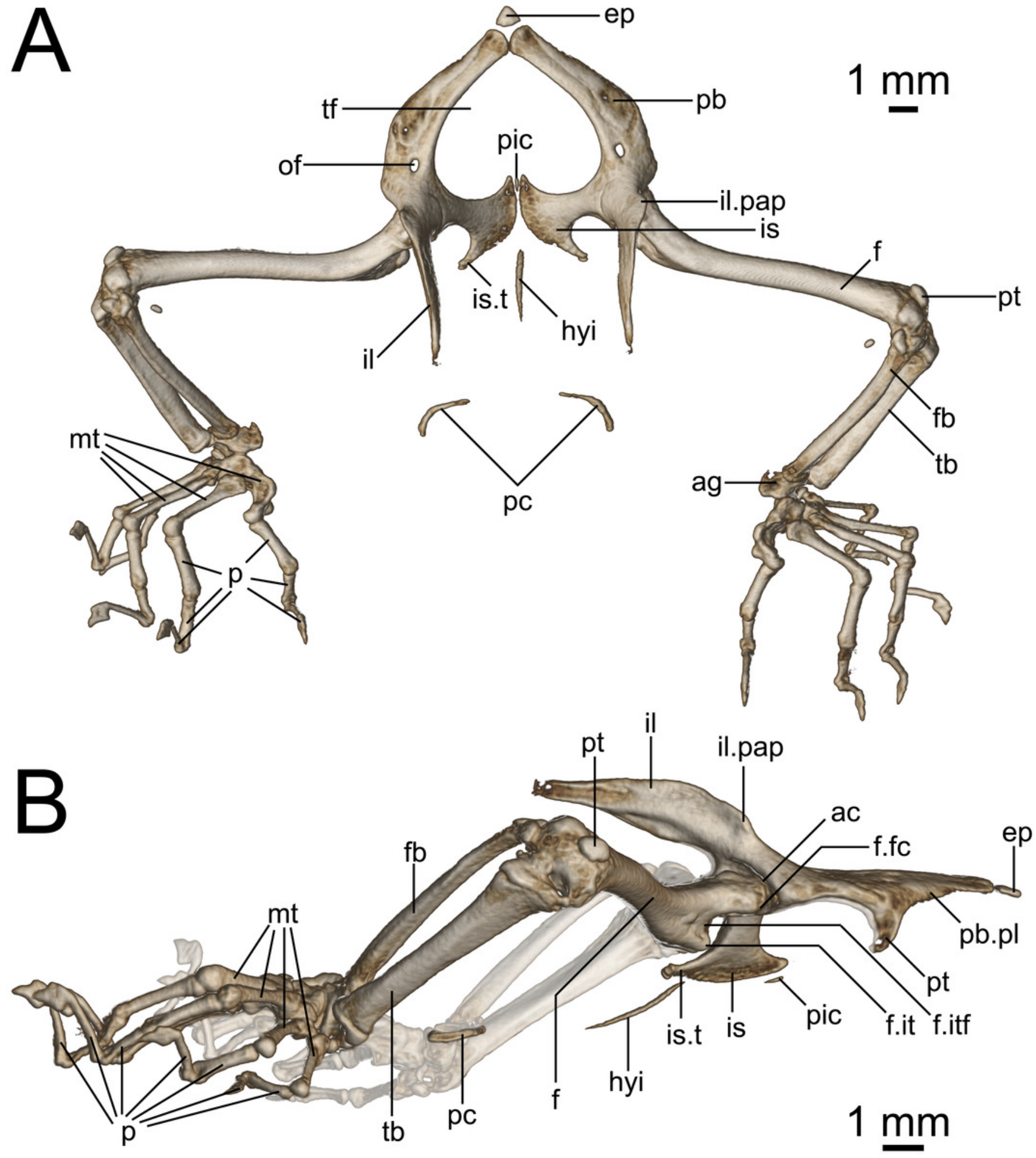